\title{
Los cismas en las órdenes militares ibéricas durante la Edad Media
}

\section{Schisms in the Iberian Military Orders during the Middle Ages}

\author{
Enrique RodríGuez-PicAvea \\ Universidad Autónoma de Madrid \\ enrique.picabea@uam.es
}

\section{RESUMEN}

El artículo estudia los cismas acaecidos en las órdenes militares ibéricas durante la Edad Media, concretamente entre mediados del siglo xII y finales del siglo xv. En primer lugar el trabajo analiza las causas de las escisiones en las órdenes militares. En segundo lugar profundiza en la naturaleza de los cismas de las órdenes militares, distinguiendo entre cismas coyunturales, cismas consolidados y cismas irreversibles. Por último, estudia las consecuencias de los cismas en las órdenes militares ibéricas.

Palabras clave: Órdenes Militares. Calatrava. Santiago. Alcántara. Castilla siglos XII-XV. Maestrazgos de Órdenes Militares

\begin{abstract}
Over the course of the history of the hispanic military orders during the Middle Ages, this article examines the naming or action of more than one master at the same time, the deposition of masters, and disputed elections. It proposes a typology for the schisms considered: conjunctural, consolidated and irreversible. The monarchy's interventions and the orders' loss of independence also receive consideration. In many respects, the article provides a holistic view of the orders, and especially that of Calatrava, during those centuries.
\end{abstract}

Keywords: Military orders. Calatrava. Santiago. Alcántara. Castile. 12th-15th centuries. Masterships of military orders

Sumario: 1. Causas de los cismas en las órdenes militares. 1.1. El comportamiento improcedente del maestre. 1.2. La sujeción de una orden militar a otra institución. 1.3. La existencia de dos modelos de poder. 1.4. El intervencionismo monárquico. 2. Naturaleza de los cismas de las órdenes militares ibéricas. 2.1. Cismas coyunturales. 2.2. Cismas consolidados. 2.3. Cismas irreversibles. 3. Consecuencias de los cismas en las órdenes militares. 3.1. Debilitamiento del maestrazgo y de la propia institución. 3.2. Incremento del control monárquico sobre las órdenes 
El vocablo cisma significa división o separación en el seno de una Iglesia o religión, o en un grupo o comunidad' Deriva del latín schisma, y éste del griego $\sigma \chi i \sigma \mu \alpha$, cuya acepción es ciertamente escisión. En el contexto histórico de lo que convencionalmente conocemos como Edad Media, la palabra cisma remite a las grandes divisiones en el seno de la Iglesia católica, y muy especialmente al denominado cisma de Occidente (1378-1417). Sin embargo, otras comunidades conocieron en aquella época sus propios cismas. Entre ellos tuvieron una especial relevancia los acaecidos en las órdenes militares ibéricas, instituciones pertenecientes a la propia Iglesia.

Las órdenes militares ibéricas nacieron y crecieron con el relevante respaldo de los monarcas, convirtiéndose así en instituciones poderosas, tanto en el ámbito político como en el social y económico ${ }^{2}$. Se trataba de entidades fuertemente jerarquizadas, al frente de las cuales se situaba un maestre. El máximo dirigente de las órdenes desplegó un notable poder, cuya importancia se acrecentó con el paso del tiempo. El ejercicio del poder por parte de los maestres propició la aparición de disidentes y la intervención de los monarcas para que la política desarrollada por las instituciones religioso-militares estuviera en consonancia con sus intereses.

La oposición al poder maestral significaba la ruptura del voto de obediencia, que era la más duramente castigada en la normativa interna de cada orden. Las expresiones de discordia contra el poder maestral conocieron diversas manifestaciones, en función del apoyo con el que el opositor o los opositores contaban dentro y fuera de la propia orden. La forma más radical de disidencia se materializaba en un cisma: una ruptura frontal que conducía a la división de la institución en dos facciones al frente de las cuales estaban el antiguo maestre y el candidato alternativo que, en ocasiones, se sentía con fuerza suficiente para intitularse como maestre de la orden. Se convierte así, desde el punto de vista historiográfico en un antimaestre. En el contexto de una institución religiosa, que depende eclesiásticamente del pontífice romano, la figura cismática del antimaestre tiene no pocos paralelismos con la del antipapa.

\footnotetext{
${ }^{1}$ Diccionario panhispánico de dudas. Real Academia Española, Madrid, 2005, voz cisma.

${ }^{2}$ La bibliografía sobre las órdenes militares ibéricas es muy abundante. Por ello remitimos a diversos balances y repertorios. Vid. Lomax D.W., Las Órdenes Militares en la Península Ibérica durante la Edad Media, Salamanca, 1976; Ayala, C. et alii, «Las Órdenes Militares en la Edad Media Peninsular. Historiografía 1976-1992, I. Reinos de Castilla y León», y «II. Corona de Aragón, Navarra y Portugal», Medievalismo. Boletín de la Sociedad Española de Estudios Medievales , 2 (1992), págs. 119-169, y 3 (1993), pp. 87-144; LADERo QuesADA, M.A., «La investigación sobre Órdenes Militares en la Edad Media hispánica durante los últimos decenios: Corona de Castilla y León», en R. IzQuierdo Benito y F. Ruiz Gómez, Las Órdenes Militares en la Península Ibérica, I. Edad Media, Cuenca, 2000, pp. 9-31; Josserand, Ph., «L'historiographie des Ordres Militaires dans les royaumes de Castille et de León. Bilan et perspectives de la recherche en histoire médiévale», Atalaya. Revue française d'études médiévales hispaniques, Paris, 9 (1998), pp. 5-44; Ayala Martínez, C. de, «Las órdenes militares hispánicas en la Edad Media. Aproximación bibliográfica», en Estudios sobre las Ór denes Militares. Lux Hispaniarum, Madrid, 1999, pp. 425-457; Ayala Martínez, C. de y Barquero GoÑI, C., «Historiografía hispánica y órdenes militares en la Edad Media, 1993-2003», en Medievalismo. Boletín de la Sociedad Española de Estudios Medievales, 12 (2002), pp. 101-161; Costa, Paula Pinto «The Military Orders Established in Portugal in the Middle Ages: A Historiografical overview», e-Journal of Portuguese History, 2.1 (2004); GARCíA-GuIJARRo RAMOS, L., «Historiography and History: Medieval Studies on the Military Orders in Spain since 1975», en Victor Mallia-Milanes (ed.), The Military Orders. 3: History and Heritage, Aldershot, 2008, 23-43.
} 
En este trabajo vamos a analizar los cismas que se produjeron en las órdenes peninsulares durante la Edad Media como la demostración más importante de la disidencia de los freires frente al poder maestral y/o el intrusismo regio. En primer lugar, nos detendremos en las causas que provocan los cismas. En segundo lugar, analizaremos la naturaleza de esos cismas. Finalizaremos el estudio con las consecuencias que se derivan de las rupturas internas acaecidas en las órdenes militares ibéricas. En consecuencia, el objetivo de esta aportación no es presentar un catálogo exhaustivo de los cismas, sino analizar sus causas, naturaleza y consecuencias.

\section{CAUSAS DE LOS CISMAS EN LAS ÓRDENES MILITARES}

\subsection{EL COMPORTAMIENTO IMPROCEDENTE DEL MAESTRE}

Entre las causas más relevantes que podían desembocar en un cisma se sitúa el comportamiento improcedente del maestre. El ejercicio del poder es producto de un pacto tanto en la tradición monástica como en el feudalismo, las dos realidades de las que participan las órdenes militares. Por eso no debe extrañar que en el seno de estas instituciones el poder sea también consecuencia de ese pacto. Un pacto entre el nivel unipersonal que representa el maestre y el nivel comunitario representado por el capítulo. Este pacto tiene como consecuencia el reparto del poder político y económico.

En su condición de supremo dirigente de su institución, la potestad del maestre se extiende tanto a la rama laica como a la rama clerical, lo que le confiere el más alto grado de representatividad de la orden en sus relaciones sociales y de poder. La privilegiada posición que ocupa el maestre en el seno de cada institución se materializa en la obediencia que le deben el resto de los freires de la misma. Esa obediencia deriva de la profesión que hacen los freires en la persona de su maestre, que es el único capacitado, con algunas excepciones, para recibirlos en la comunidad. Por su parte, el maestre debe su dignidad a la elección que los miembros de la institución han verificado en su persona.

En lógica consonancia con lo expresado anteriormente, el poder maestral deriva de un pacto con los miembros de la comunidad y no es un poder absoluto, ya que está limitado por la responsabilidad que tiene ante los freires que le han elegido, reunidos en el capítulo. La ruptura del pacto por parte del maestre podía acabar con su destitución. Esto era así teóricamente. Por ejemplo, la normativa de la orden de Santiago contemplaba esta posibilidad. Sin embargo, en 1246 el papa Inocencio IV especificaba que los mandatos de los maestres de esta institución, como los de cualquier otro prelado superior designado por el procedimiento de elección, debían ser considerados como perpetuos ${ }^{3}$.

Como consecuencia de ese pacto, el maestre estaba obligado a proporcionar a los integrantes de su comunidad los recursos necesarios para su mantenimiento y para el adecuado desarrollo de sus funciones: alimentos, ropas, cabalgaduras y equipos militares. Lógicamente, para cumplir con esa obligación el maestre debía tener

${ }^{3}$ Quintana Prieto, A., La documentación pontif cia de Inocencio IV (1243-1254), 2 vols., Roma, $1987, \mathrm{n}^{\circ} 254$. 
cierta capacidad de maniobra para gestionar el patrimonio y las rentas de la orden, que aparecía reunido en una "mesa común", sin distinción entre lo que correspondía al maestre y al resto de los freires que integraban la comunidad. Por eso el maestre tenía la responsabilidad de gestionar adecuadamente el patrimonio de la orden, ya que no sólo de su eficaz gestión dependían los freires, sino también los mercenarios y otros asalariados, y el costoso mantenimiento de las fortalezas.

Aproximadamente hasta mediados del siglo XIII, las órdenes funcionaron en virtud de ese pacto de connotaciones monásticas y naturaleza feudal al que hemos aludido. Lo cierto es que, una vez en el poder, los maestres intentarían gobernar las órdenes con una tendencia más monárquica, personalista y autoritaria de lo que sus freires deseaban y estos últimos, a través del capítulo y de otros órganos corporativos, intentarían limitar la autoridad maestral hasta el punto de obligarles en ocasiones a renunciar a su cargo ${ }^{4}$.

Entre todas las órdenes militares ibéricas, las de Calatrava y Santiago conocieron las manifestaciones más acentuadas de esa presión corporativa de los freires. No es descartable que, como resultado de esa coacción, y durante el primer siglo de vida de estas instituciones, un número importante de maestres se viera obligado a renunciar a su dignidad antes de su muerte, cuando en circunstancias normales el maestrazgo era perpetuo. Esta circunstancia constituye todo un síntoma de la debilidad institucional de las órdenes en sus primeros tiempos y el triunfo inicial del corporativismo pactista, dada la naturaleza conventual y aristocrática de dichas instituciones ${ }^{5}$.

En ocasiones, la presión corporativa no era suficiente para que el maestre renunciara a su dignidad. Considerando entonces los freires que su superior había incumplido alguno de los términos del pacto, se rebelaban contra su autoridad y propiciaban cismas, liderados por antimaestres. Varios son los casos que podemos presentar como cismas derivados de una actuación inadecuada de los maestres.

El primero, por orden cronológico, se produjo en fechas muy tempranas, cuando la cofradía calatrava estaba en proceso de consolidación. Tras la renuncia de Fernando Escaza al maestrazgo por razones de edad, Martín Pérez de Siones fue elegido maestre de la orden de Calatrava en 1170, cuando ocupaba el cargo de comendador de Calatrava ${ }^{6}$. Al poco tiempo, y como consecuencia del descontento que provocó la orden

${ }^{4}$ Sobre todo lo anterior vid. Ayala Martínez, C. de, «Maestres y maestrazgos en la Corona de Castilla (siglos XII-Xv)», en Las Órdenes Militares en la Península Ibérica, I. Edad Media R. IzQuIERDo Benito y F. Ruiz Gómez (eds.), Cuenca, 2000, pp. 325-378; Ayala Martínez, C., Las Órdenes militares Hispánicas en la Edad Media (siglos XII-XV), Madrid, 2003, pp. 191-208; RodríGuez-PICAVEA, E., Los monjes guerreros en los r einos hispánicos. Las ór denes militares en la Península Ibérica durante la Edad Media, Madrid, 2008, pp. 321-327.

${ }^{5}$ Ayala Martínez, C. de, «Las órdenes militares en el siglo XiII castellano. La consolidación de los maestrazgos», Anuario de Estudios Medievales, 27/1 (1997), 239-279, pp. 242-249.

${ }^{6}$ Sobre el maestrazgo de Martín Pérez de Siones vid. O’Callaghan, J.F., «The Order of Calatrava: years of crisis and survival, 1158-1212», The Meeting of Two Worlds. Culture Exchange between East and West during the period of the Crusades, Studies in Medieval Cultur e, XXI, Western Michigan University, 1986, 419-430; RodríGuez-Picavea Matilla, E., Las órdenes militares y la frontera. La contribución de las ór denes a la delimitación de la jurisdicción territorial de Castilla en el siglo XII, Madrid, 1994, pp. 84-91. 
de Martín Pérez de Siones de pasar a cuchillo a 200 musulmanes cautivos, algunos caballeros eligieron por maestre a Diego García, que se retiró con sus partidarios al castillo de Salvatierra. Sin embargo, el cisma duró poco tiempo, ya que los caballeros rebeldes y el antimaestre volvieron pronto a la obediencia del legítimo maestre?

Alrededor de un cuarto de siglo más tarde, documentamos otro cisma en la misma institución. A raíz de la crisis de la orden tras la derrota de Alarcos (1195) frente a los almohades, que supuso la pérdida de su sede y la del Campo de Calatrava. Entonces, los calatravos aragoneses aprovecharon la coyuntura para elegir como maestre de Alcañiz a García López de Moventa, que contó con el apoyo del monarca aragonés. Se iniciaba así un cisma, que, mientras duró, supuso la independencia de hecho de la rama aragonesa de la orden de Calatrava. La causa justificativa pudo ser la ineficacia del maestre, cuya actuación no pudo impedir la pérdida del Campo de Calatrava y de la sede fundacional de la institución. Pero por detrás estaban los deseos de escindirse de la orden por parte de los calatravos aragoneses y del rey de Aragón. Desde entonces, García López de Moventa se tituló maestre en Alcañiz con el apoyo del monarca aragonés, que deseaba la independencia de la rama calatrava de su reino para desplegar sobre ella un más estrecho control.

En 1205, el maestre Martín Martínez acudió a Aragón atendiendo al mandamiento del papa Inocencio III, quien, por solicitud de Pedro II de Aragón, había ordenado a los freires de Salvatierra y Uclés que acudieran a la frontera aragonesa para combatir contra los musulmanes. El viaje sirvió para sellar un acuerdo en 1206 con el maestre cismático, que propició la renuncia del aragonés al maestrazgo a cambio del reconocimiento del título de comendador mayor y lugarteniente del maestre en Aragón para García López de Moventa y sus sucesores.

Sin embargo, ese mismo año, y aprovechando la ausencia del maestre, tuvo lugar el nombramiento de Rodrigo Díaz como nuevo maestre de Salvatierra -nombre que recibía la orden, ya que en esta fortaleza estaba su nueva sede. A partir de entonces, Martín Martínez actuó, con el apoyo del monarca aragonés, como "honorabili magistro domus de Alcaniz", hasta su muerte acaecida hacia 1211. No sabemos si el fallecimiento del maestre supuso también el fin del cisma. Tal vez se prolongó, y entonces pudo ser la causa del viaje que en 1215 realizó el maestre Rodrigo Garcés para ocuparse de cierto conflicto surgido en el castillo y villa de Alcañiz. Allí murió y fue sepultado en el convento de la encomienda mayor aragonesa ${ }^{8}$.

Poco más de un siglo después, algunos indicios pueden relacionarse también con el comportamiento improcedente del máximo dirigente de otra orden militar cisterciense. Así, en enero de 1318, el maestre de Calatrava, García López de Padilla, tras una tumultuosa visita al convento de Alcántara, procedió a la destitución de Ruy Vázquez como maestre de Alcántara, y a la confirmación de su sucesor Suero Pérez. Según

${ }^{7}$ Rades y Andrada, F., Chronica de las Tres Ordenes y Cauallerias de Sanctiago, Calatraua y Alcantara: en la qual se trata de su origen y successo, y notables hechos en armas de los maexts. y caualleros de ellas: $y$ de muchos señor es de titulo y otros nobles que descienden de los maestres: y de muchos otr os linajes de España, Toledo, 1572 (ed. facs. Barcelona, 1980 y Valencia, 1994), Chronica de Calatraua, fols. 17r-18r.

${ }^{8}$ Rades y Andrada, Chronica de Calatraua, fol. 32v. 
el propio documento la destitución de la máxima dignidad alcantarina se produjo como consecuencia de las quejas de varios comendadores de la orden sobre el comportamiento del propio Ruy Vázquez ${ }^{9}$. Los cronistas posteriores siguen esta línea de argumentación y justifican la destitución del maestre por su inadecuada actuación ${ }^{10}$. Sin embargo, es posible que su cese estuviera relacionado con una injerencia en la vida interna de la orden del infante don Pedro, uno de los tutores que controlaban por entonces la monarquía del rey-niño Alfonso XI. La razón de esta intromisión pudo ser un posible cambio de bando del maestre alcantarino, que se habría pasado al partido del infante-tutor rival ${ }^{11}$. Parece claro que se produjo una división entre los freires de Alcántara, aunque no consta documentalmente que las discordias cristalizaran en un cisma.

El último de los ejemplos relacionado con un comportamiento improcedente del maestre coincide con el conflictivo gobierno del calatravo García López de Padilla (1297-1329), que conoció una fuerte oposición por parte de los freires de la orden. La crisis final que acabaría con su destitución se desencadenaría en 1323. La causa de esta crisis estaba, una vez más, en la inadecuada actuación del maestre. La excusa para desatar la rebelión abierta contra García López de Padilla fue su aciaga participación en una expedición contra los musulmanes granadinos, agravada por su supuesta huida del campo de batalla. El protagonista de la revuelta fue Juan Núñez de Prado, clavero de la orden, respaldado por un número importante de caballeros de la institución. El clavero organizó la resistencia desde Villa Real, ganándose así el apoyo de este concejo de realengo, cuyos pobladores habían sufrido los agravios del maestre y sus presiones para que se pasaran al señorío calatravo ${ }^{12}$.

En 1325, cuando Alfonso XI de Castilla accedió a la mayoría de edad, el clavero y los freires rebeldes acudieron a Valladolid para presentar formalmente sus acusaciones contra el maestre ante la corte regia. Las acusaciones se extendían a toda la etapa del maestrazgo de García López de Padilla y se sustanciaron en cuatro cuestiones. La más importante era la dejación de fortalezas, que el maestre había desabastecido. Esta fue la razón, según los rebeldes, de que se perdieran, entre otras, las fortalezas de Alcaudete, Locubín, Susaña, Chist y Mathet. No menos grave era la acusación de haber huido del combate en el transcurso de la batalla de Baena, abandonando así a los freires de la orden que lo acompañaban. El tercero de los cargos contra el maestre era el de autoritarismo y crueldad en el trato a sus freires. Por si todo lo anterior no

${ }^{9}$ Archivo Histórico Nacional, Órdenes Militares, sign. 1345c, fols. 161-162; Real Academia de la Historia, Colección Salazar, I-41, fols. 209-212. Publ. Ortega y Cotes, I.J.; Álvarez de Baquedano, F.; Ortega ZúÑIga y Aranda, P., Bullarium Ordinis Militiae de Calatrava, Madrid, 1761, ed. facsímil, Barcelona, 1980, pp. 173-176.

${ }^{10}$ Rades y Andrada, Chronica de Calatraua, fol. 15; Yepes, A., Cronica General de la Or den de San Benito, Valladolid, 1621, III, p. 434; Torres y TAPIA, A. de, Crónica de la Orden de Alcántara, 2 vols., Madrid, 1763, I, p. 509.

${ }^{11}$ Novoa Portela, F., «Los Maestres de la Orden de Alcántara durante los reinados de Alfonso XI y Pedro I», Historia, Instituciones y Documentos, 29 (2002), 317-335.

${ }^{12}$ Los acontecimientos relacionados con este cisma los conocemos por las versiones cronísticas. Vid. Crónica de Alfonso XI, en Crónicas de los Reyes de Castilla, I, ed. C. Rosell, «Biblioteca de Autores Españoles», Madrid, 1953, 171-392, pp. 195-196 y 200; Gran Crónica de Alfonso XI, ed. D. Catalán, 2 vols., Madrid, 1976, pp. 362-363 y 382; RAdes y ANDrada, Chronica de Calatraua, fols. 50r-52r. 
fuera suficiente, el maestre fue acusado también de atacar a lugares y vasallos del realengo, particularmente los pertenecientes a la jurisdicción de Villa Real ${ }^{13}$.

La gravedad de las acusaciones propició que el maestre fuera citado ante el tribunal real. La reacción de don García, temiendo una sentencia desfavorable, fue huir a Alcañiz, cabeza de los señoríos aragoneses de Calatrava. Al temor del maestre debió contribuir también el apoyo que el clavero rebelde tenía en la corte. El propio monarca castellano se habría decantado probablemente del lado de los rebeldes dado el filoaragonesismo del que había hecho gala García López de Padilla a lo largo de su gobierno. Los acontecimientos que se sucedieron avalarían estas sospechas, ya que, tras la huida del maestre, Alfonso XI ordenó a los freires opositores que organizaran un irregular capítulo, que eligió como nuevo maestre a Juan Núñez de Prado ${ }^{14}$.

El cisma se prolongó, ya que desde el convento-fortaleza de Alcañiz, el depuesto maestre intentó hacer valer sus derechos ante el capítulo general de la orden del Císter. Los cistercienses, a través del abad de Monsalud, primero, y del de Morimond, después, reconocieron efectivamente la legitimidad de su cargo y le restituyeron en la posesión del maestrazgo.

No obstante, ante el respaldo con el que contaba Juan Núñez de Prado por parte del monarca castellano y de varios caballeros de la orden, y las villas y castillos calatravos que conservaba, en 1329, García López de Padilla decidió renunciar al maestrazgo a cambio de mantener a su servicio diez caballeros y del disfrute vitalicio de de las encomiendas de Zorita y El Collado y de cuantas villas y castillos tenía la orden en los reinos de Aragón y Valencia, con sus rentas ${ }^{15}$.

Al parecer, el incumplimiento por parte de Juan Núñez de Prado de algunos términos del acuerdo anterior provocó que don García volviera a reivindicar sus derechos a ocupar la más alta dignidad de la institución, desde su sólida posición en Alcañiz y con el más que probable apoyo de la monarquía aragonesa. García López de Padilla murió hacia 1336, sin haber renunciado al maestrazgo calatravo ${ }^{16}$. Esta circunstancia, y la continuidad del apoyo de la Corona aragonesa, tuvieron como consecuencia la prolongación del cisma hasta el acuerdo alcanzado en agosto de 1348, ante las Cortes reunidas en Zaragoza. La avenencia fue posible a cambio de otorgar mejores derechos y una mayor autonomía a las encomiendas aragonesas de la orden ${ }^{17}$.

${ }^{13}$ En octubre de 1325, las Def niciones promulgadas por el abad de Palazuelos, en representación del de Morimond, recogían varios de los cargos imputados al maestre García López de Padilla, particularmente los relacionados con el perjuicio ocasionado al patrimonio de la orden. Vid. O'CALLAGHAN, J.F., «The Earliest 'Difiniciones' of the Order of Calatrava, 1304-1383», Traditio, 17 (1962), 255-284, pp. 269-273.

${ }^{14}$ Ayala Martínez, C. de, «Un cuestionario sobre una conspiración. La crisis del maestrazgo de Calatrava en 1311-1313», en Aragón en la Edad Media, XIV -XV. Homenaje a la pr ofesora Carmen Orcástegui Gros, Zaragoza, 1999, I, pp. 73-89.

${ }^{15}$ Archivo Histórico Nacional, Órdenes Militares, carp. 464, nº 224; sign. 1346c, fols. 44-47.

${ }^{16}$ Caruana Gómez de Barreda, J., «La Orden de Calatrava en Alcañiz», Teruel, 8 (1952), 5-175, pp. 107-108.

${ }^{17}$ Archivo Histórico Nacional, Órdenes Militares, sign. 1347c, fols. 59-63; Ortega y Cotes, I.J.; Álvarez de Baquedano, F.; Ortega Zúñiga y Aranda, P., Bullarium Ordinis Militiae de Calatrava, pp. 756-760. 


\subsection{LA SUJECIÓN DE UNA ORDEN MILITAR A OTRA INSTITUCIÓN}

Naturalmente, la actuación inadecuada del maestre generaba una división en el seno de su orden. No era, sin embargo, el único motivo que provocaba discordia entre los freires de una misma institución, y podía conducir a un cisma. Por ejemplo, la sujeción de una orden militar a otra, cuyo maestre actuaba teóricamente como superior de la primera, también podía ser causa de una escisión.

Tal es el caso de la división que se produjo en el seno de la orden de San Julián del Pereiro, en el contexto del complejo proceso de sujeción a la orden de Calatrava. Desde finales del siglo XII, los calatravos intentaron recuperar el control teórico que la bula papal de 1187 les había reconocido sobre la orden del Pereiro. Para ello, Calatrava pudo intentar atraerse a su causa, mediante presiones, a freires de la institución leonesa, con el objetivo de que convencieran a su maestre para que aceptara la autoridad superior de su homólogo calatravo. Fuera como fuese, parece que un sector de los freires sanjulianistas era proclive a la causa de Calatrava. Esta circunstancia, unida al interés de Alfonso IX de León, propició que se alcanzara un importante acuerdo en julio de 1218. El pacto, que fue respaldado por el propio monarca, convertía al maestre calatravo en el inmediato superior jerárquico de la orden de San Julián del Pereiro, institución que, a cambio, recibiría la fortaleza de Alcántara y las restantes posesiones calatravas en el reino de León. El maestre calatravo Gonzalo Ibáñez, aprovechando la nueva situación, puso al frente de la orden leonesa a uno de sus freires. Probablemente este freire fue el maestre García Sánchez (1219-1229).

El acuerdo de 1218 y la imposición de un maestre procalatravo contaron con la oposición de una parte de los freires sanjulianistas, que reclamaron ante la curia romana. Una bula de Honorio III de 1224 satisfacía esta demanda, al revocar el nombramiento del maestre impuesto por Gonzalo Ibáñez y otorgar la razón al sector de freires opuestos a la dependencia de Calatrava ${ }^{18}$. El Papa reconocía que los calatravos habían actuado al margen de la jurisdicción eclesiástica. Todo apuntaba a que comenzaba a fraguarse un cisma, y desde luego los freires alcantarinos estaban divididos. Sin embargo, no parece que la bula papal se cumpliera. Probablemente, el respaldo del monarca leonés al sector procalatravo lo impidió. Las disidencias de los opositores fueron diluyéndose, o, al menos, eso se deduce de la ausencia de nuevas noticias documentales sobre el tema. Poco después, en 1230, la unificación de Castilla y León contribuyó a consolidar la nueva realidad de una orden de Alcántara dependiente jerárquicamente del maestre de Calatrava, y restó sentido al leonesismo o al castellanismo de las órdenes nacidas en ambos reinos ${ }^{19}$.

${ }^{18}$ Mansilla, D., La documentación pontif cia de Honorio III (1216-1227), Roma, 1965, no 522.

19 Sobre la orden de San Julián del Pereiro y los orígenes de la orden de Alcántara pueden consultarse las obras de O'CALLAGHAN, «The foundation of the Order of Alcántara, 1176-1218», pp. 471-486; CORRAL VAL, L., Los monjes soldados de la or den de Alcántara en la Edad Media. Su or ganización institucional y vida religiosa, Madrid, 1999, pp. 75-102; Novon Portela, F., La Orden de Alcántara y Extr emadura (siglos XII-XIV), Mérida, 2000, pp. 23-38; y AYALA, Las Órdenes militares Hispánicas en la Edad Media, pp. 81-88. 


\subsection{LA EXISTENCIA DE DOS MODELOS DE PODER}

En la Baja Edad Media ibérica se desarrollan básicamente dos modelos de ejercicio del poder: el monárquico de tendencia autoritaria y el aristocrático de vocación pactista. Los maestres, influenciados por los reyes, intentaron desarrollar el primero, apoyados por algunos seguidores. Mientras que la mayoría de los freires, representados en el capítulo, fueron defensores del segundo y para ello se aliaron con la nobleza.

La confrontación entre estos dos modelos se manifestó con claridad durante el reinado de Alfonso X (1252-1284), en un contexto de enfrentamiento regio con la nobleza. El maestre de Santiago, Pelayo Pérez Correa, dio varias pruebas de autoritarismo durante su gobierno, y del manejo desmedido de los recursos de la orden, con el objetivo de reforzar el maestrazgo. La actuación maestral provocó la contestación de un sector de los freires, al menos en 1245 y en 1263-1264. Sin embargo, la situación no llegó a desembocar en cisma gracias a la intervención de los pontífices romanos, que desautorizaron las actuaciones abusivas del maestre, sin negar su potestad como superior de la institución. Los papas intentaban así dar respuesta a las quejas de los freires, pero manteniendo al mismo tiempo el reconocimiento de la jurisdicción que correspondía a la dignidad maestral ${ }^{20}$.

Más claro resulta el antagonismo entre los dos modelos políticos en la orden de Calatrava. El maestre Pedro Ibáñez (1254-1267) era el candidato del monarca, y el partidario del intervencionismo regio, mientras que los freires tenían su propio candidato, el clavero Juan González, que representaba al sector mayoritario. En 1265, y como consecuencia de la división en la orden sobre los dos modelos de gobierno, el maestre, según nos informa el cronista Rades, "viendose muy viejo tomo como Coadjutor del Maestradgo a don Iuan Gonçalez Clavero, y consintio que tambien se llamase Maestre" ${ }^{21}$. Como consecuencia de ello se estableció una auténtica diarquía, hecho sin precedentes en la trayectoria de la orden, que consagraba el triunfo de la facción aristocratizante. Al mismo tiempo permanecía el maestre al frente de la milicia, sin renunciar a su dignidad por motivos de edad como había sucedido en casos anteriores. La situación respondía muy probablemente a las presiones regias para que el valedor de su política se mantuviera al frente de la orden. La insólita diarquía se mantuvo en el gobierno de la institución hasta el fallecimiento de Pedro Ibáñez en 1267. Esta anomalía sólo se explica por la existencia de dos modelos políticos: el monárquico y el pactista de base corporativa, y debió ser producto de una solución pactada, detrás de la cual estaba el interés del rey por la continuidad de su fiel aliado ${ }^{22}$.

El dilatado maestrazgo de García López de Padilla (1297-1329) fue un período donde abundaron las disensiones internas en el seno de la orden. Se trata de una etapa inmersa en el proceso clave mediante el cual los maestres van consolidando su poder

${ }^{20}$ Quintana Prieto, A., La documentación ponti f cia de Inocencio IV (1243-1254), 2 vols., Roma, 1987, no 167, 175, 176, 212 y 254 ; RodRíGUEz R. DE LAMA, I., La documentación pontif cia de Urbano IV (1261-1264), Roma, 1981, ñ 165, 175, 201 y 204.

${ }^{21}$ Rades y ANDrada, Chronica de Calatraua, fol. 45r.

${ }^{22}$ Ayala, «Las órdenes militares en el siglo XIII castellano. La consolidación de los maestrazgos», pp. 262-263. 
y la autonomía económica necesaria para ejercerlo, materializada en la creación de la mesa maestral. En contrapartida, los freires van consiguiendo paulatinamente que el capítulo de la orden sea expresión de su fuerza corporativa y las encomiendas se conviertan en recompensas que les permitan disfrutar de una parte de los recursos de la orden. Esa tensión en el reparto del poder y entre los dos modelos políticos posibles se materializa en la etapa de gobierno de García López de Padilla. El propio maestre había sido opositor al corto gobierno de su antecesor Diego López San Zoil (1296-1297), ya que como clavero de la orden había obtenido en la elección maestral el respaldo de varios freires calatravos ${ }^{23}$.

En la primera etapa del maestrazgo de López de Padilla tiene lugar un cisma en el interior de la orden, encabezado por el comendador mayor, Gutierre Pérez. La división se prolongó hasta febrero de $1301^{24}$, cuando los dos freires se comprometieron a aceptar la decisión arbitral del abad de Morimond ${ }^{25}$. La decisión fue favorable a don García. Sin embargo, antes de que finalizara ese año, el abad cisterciense de San Pedro de Gumiel, actuando en nombre del abad de Morimond, depuso al maestre y en un capítulo, donde fueron claves las presiones del infante don Enrique, tutor de Fernando IV de Castilla, se procedió a la elección de frey Alemán, comendador de Zorita, como nuevo maestre de Calatrava ${ }^{26}$. Sin embargo, ante la irregularidad cometida, y a instancias del pontificado, el capítulo general del Císter y el abad de Morimond, como visitador de Calatrava, restituyeron en su dignidad a García López de Padilla en febrero de $1302^{27}$. Con todo, frey Alemán pudo titularse maestre hasta mayo de ese mismo año ${ }^{28}$.

La disconformidad con la política del maestre debe relacionarse con el autoritarismo con el que debió llevar a cabo su gobierno. Por otra parte, su evidente filoaragonesismo, en una coyuntura de guerra entre Castilla y la Corona de Aragón (1296-1304), es un factor que puede explicar que miembros de la corte tan significados como el infante don Enrique maniobraran para arrebatarle el poder. Al mismo tiempo, los freires de una orden fundamentalmente castellana verían en su estrecha relación con Jaime II de Aragón un argumento más para justificar su rebelión, sabiendo que esta circunstancia podría asegurarles el apoyo de miembros de la corte regia.

No obstante, la oposición al maestre no dependía solamente de factores coyunturales. En 1307 llegaron al capítulo general cisterciense nuevas denuncias contra García López de Padilla, tal vez respaldadas por algún miembro de la corte. Sin embargo, el abad de Morimond, que se desplazó hasta el reino de Castilla para aclarar las acusaciones ${ }^{29}$, se encontró con que Fernando IV y su madre María de Molina le

${ }^{23}$ Rades y Andrada, Chronica de Calatraua, fol. 48r.

${ }^{24}$ O'Callaghan, J.F., «The Affiliation of the Order of Calatrava with the Order of Cîteaux», Analecta Sacri Ordinis Cisterciensis, XV (1959), 175-178, y XVI (1960), 3-59 y 255-292, p. 256.

${ }^{25}$ Real Academia de la Historia, Colección Salazar, sign. I-41, fols. 5-7; Benavides, A., Memorias de don Fernando IV de Castilla, 2 vols., Madrid, 1860, II, pp. 241-242.

${ }^{26}$ Archivo Histórico Nacional, Órdenes Militares, carp. 462, nº 172.

${ }^{27}$ Rades y Andrada, Chronica de Calatraua, fol. 49r ; Archivo Histórico Nacional, Órdenes Militares, carp. $427, \mathrm{n}^{\circ} 157$; sign. $1345 \mathrm{c}$, fol. 16.

${ }^{28}$ Archivo Histórico Nacional, Órdenes Militares, carp. 462, no 171; sign. 1345c, fols. 11-12.

${ }^{29}$ Archivo Histórico Nacional, Órdenes Militares, sign. 1345c, fol. 31. 
aseguraron la lealtad del maestre ${ }^{30}$. Sin embargo, la existencia de rebeldes y fugitivos de la orden era una realidad y el abad cisterciense tuvo que solicitar al rey que no fueran amparados en la corte ${ }^{31}$.

En cualquier caso, esta oposición no fue nada si la comparamos con la que se desarrolló a raíz de la revuelta de marzo de 1311, cuando, aprovechando la estancia del maestre en tierras aragonesas, un grupo de freires de la orden, encabezados por el clavero Fernando Rodríguez, ocuparon violentamente las fortalezas de Calatrava y Salvatierra, y le exigieron que abandonara su dignidad, amenazándole, en caso contrario, con la deposición y la prisión. Incluso idearon un plan para asesinar al propio García López de Padilla ${ }^{32}$.

El conflicto no se resolvió definitivamente a favor del maestre hasta el primer semestre de 1313, cuando una comisión de abades cistercienses investigó la cuestión por orden del abad de Morimond. El 1 de mayo de 1313, los abades asistieron al capítulo celebrado en el convento de Calatrava. Inmediatamente después procedieron a interrogar al maestre y a otros testigos sobre la revuelta. La respuesta de la comisión cisterciense no la conservamos, pero sin duda resultó favorable a García López de Padilla. Durante el tiempo transcurrido entre la toma violenta de las fortalezas del Campo de Calatrava y la definitiva resolución, el maestre pudo conservar el poder y hacer frente a los rebeldes gracias al apoyo papal, su alianza con el infante don Pedro, hermano de Fernando IV, y el respaldo de Jaime II de Aragón ${ }^{33}$.

\subsection{EL INTERVENCIONISMO MONÁRQUICO}

El intrusismo regio en las elecciones maestrales provocaba en no pocas ocasiones la oposición de un buen número de freires, que apoyaban a un candidato alternativo y así se consagraba la existencia de un cisma. En sentido inverso, el monarca podía apoyar a la facción opositora frente al maestre elegido con la mayoría de los votos. El intervencionismo regio contribuía así a que el cisma se consolidara, introduciendo un importante factor de desequilibrio en la vida interna de las órdenes militares.

La primera noticia sobre el intervencionismo regio como causa de un posible cisma en las órdenes militares se remonta a finales del siglo XII ${ }^{34}$. Procede del historiador Francisco de Rades, quien da cuenta de la intervención de la orden de Santiago en la guerra castellano-leonesa de 1196-1197, en la que Alfonso IX de León se alió con los almohades para atacar a los castellanos en varios frentes y arrasar la Tierra

\footnotetext{
${ }^{30}$ O'Callaghan, «The Affiliation of the Order of Calatrava with the Order of Citteaux», p. 258.

${ }^{31}$ Ortega y Cotes, I.J.; Álvarez de Baquedano, F.; Ortega Zúñiga y Aranda, P., Bullarium Ordinis Militiae de Calatrava, p. 160.

${ }^{32}$ Archivo Histórico Nacional, Órdenes Militares, sign. 1345c, fol. 98-99; AYala, «Un cuestionario sobre una conspiración. La crisis del maestrazgo de Calatrava en 1311-1313», pp. 87-89.

${ }_{33}$ Ayala, «Un cuestionario sobre una conspiración. La crisis del maestrazgo de Calatrava en 13111313», pp. 77-82.

${ }^{34}$ Rades y Andrada, Chronica de Sanctiago, fols. 16v-17r, 20v, 26 y 27v; Orozco, P. de y J. de la PARra, [Primera] Historia de la Or den de Santiago. Manuscrito del siglo XV, de la Real Academia de la Historia, prólogo de Diego de Angulo, introducción, transcripción, notas y apéndice del Marqués de Siete Iglesias, Badajoz, 1978, p. 362.
} 
de Campos. El maestre de Santiago, Gonzalo Rodríguez, junto a la mayoría de sus freires, se puso del lado del monarca castellano para intentar hacer frente a la alianza entre los leoneses y los musulmanes. Sin embargo, parece que algunos freires leoneses apoyaron a Alfonso IX, que pudo promover entonces la elección del antimaestre Gonzalo Ordóñez ${ }^{35}$. De ser cierta esta información, estaríamos ante el primer enfrentamiento bélico entre freires de la misma orden. Sin embargo, parece difícil que tal circunstancia se produjera, teniendo en cuenta que el monarca leonés se había aliado a los almohades y el Papa lo había excomulgado, al tiempo que había puesto su reino en entredicho. Incluso se ha llegado a cuestionar la participación de los santiaguistas castellanos, teniendo en cuenta que en 1197 los almohades atacaron Uclés y Alarcón, y la orden debió concentrar sus esfuerzos en la defensa de estas plazas estratégicas ${ }^{36}$.

Unas décadas más tarde, tuvo lugar el primero de los casos contrastados de intervencionismo regio en las elecciones maestrales, que se remonta al reinado de Fernando III (1217-1252). Se trata de la elección de Fernando Ordóñez como maestre calatravo en 1243. Los sucesos que propiciaron esta intervención regia se iniciaron tres años antes, cuando fue elegido como maestre Gómez Manrique y una parte importante de clérigos y caballeros votaron a favor del comendador mayor Fernando Ordóñez, el candidato regio. Los disidentes no aceptaron el resultado y negaron la obediencia al maestre, lo que propició una importante escisión interna en la institución. Para resolver el cisma, Fernando III instó a que Gómez Manrique renunciara a su dignidad, procediéndose entonces a una nueva elección maestral, en la que salió elegido, esta vez sin aparente oposición, Fernando Ordóñez. De este modo, la intervención regia había condicionado de forma decisiva la voluntad de los freires de la orden. En compensación, el otrora maestre quedaba residiendo en la casa fuerte de Alvillos, en Tierra de Campos, con el título de comendador mayor y sujeto directamente a la Sede Apostólica, no sometiéndose así a la jurisdicción del nuevo maestre ${ }^{37}$.

Poco tiempo después, a comienzos del reinado de Alfonso X, el monarca impuso a su candidato Pedro Ibáñez, hasta entonces maestre de Alcántara, como máxima dignidad de la orden de Calatrava ${ }^{38}$. No consta, sin embargo, que tal imposición desencadenara un cisma en la institución, aunque es muy posible que pronto se articulara una oposición frente al candidato impuesto por el rey, pero el respaldo de Alfonso $\mathrm{X}$ a su fiel aliado impidió que la discordia se convirtiera en un asunto más serio ${ }^{39}$, al menos hasta el establecimiento de la diarquía en 1265.

Para encontrar un nuevo caso de intervencionismo regio como causa de una escisión en una orden militar hay que situarse en el inicio del reinado efectivo de Alfonso XI de Castilla (1325-1350), y a este cisma ya hemos tenido ocasión de aludir.

${ }^{35}$ Estos hechos los conocemos exclusivamente por la tardía versión del cronista Rades y no está contrastada por otras fuentes. Vid. Rades y AndRada, Chronica de Sanctiago, fol. 20v. Uno de los más importantes historiadores de la orden duda de que los santiaguistas lucharan contra el reino de León. Vid. LomaX, D.W., La Orden de Santiago (1170-1275), Madrid, 1965, p. 30.

${ }^{36}$ Rades y Andrada, Chronica de Sanctiago, fol. 20v; Lomax, La Orden de Santiago, p. 10.

${ }^{37}$ Rades y Andrada, Chronica de Calatraua, fols. 40v-41r.

${ }^{38}$ Rades y Andrada, Chronica de Alcantara, fol. 10v.

${ }^{39}$ Ayala, «Las órdenes militares en el siglo XIII castellano. La consolidación de los maestrazgos», pp. 262-263. 
La escisión comenzó por razón de divisiones internas entre los freires de la orden de Calatrava, pero el apoyo regio a los rebeldes permitió que la ruptura se consolidara y que el maestre García López de Padilla permaneciera en Alcañiz reivindicando infructuosamente el maestrazgo hasta su muerte (1336). Parece indiscutible que el apoyo regio fue factor esencial para que el nuevo maestre Juan Núñez de Prado pudiera conservar su maestrazgo $0^{40}$.

Por la misma época encontramos ejemplos nítidos del intrusismo regio en la orden de Alcántara. En 1337, al estallar la guerra con Portugal, Alfonso XI ordenó al maestre alcantarino Rodrigo Pérez que contribuyera al levantamiento del cerco de Badajoz. Una vez abandonado el asedio, las tropas portuguesas realizaron una correría por las tierras del señorío de Alcántara. A partir de entonces, la actitud del maestre alcantarino fue ambigua y no respondió a los deseos del monarca castellano. Alfonso XI forzó la renuncia de Rodrigo Pérez al maestrazgo e influyó decisivamente para que la máxima dignidad alcantarina recayera en un hombre de su entera confianza, el despensero mayor del rey Gonzalo Martínez de Oviedo, cuya elección, que atentaba contra la normativa de la orden, contó con la presencia del abad cisterciense de San Isidoro del Campo de Sevilla y el maestre de Calatrava, y con el beneplácito del abad de Morimond, que acompañaba por entonces al monarca ${ }^{41}$.

El nombramiento como maestre de Alcántara de un fiel colaborador de Alfonso XI no solucionó el problema, ya que Gonzalo Martínez se vio complicado en intrigas cortesanas protagonizadas por la favorita regia Leonor de Guzmán, lo que predispuso al rey en contra del maestre alcantarino. Fuera por este motivo, o por el convencimiento de que era lo más beneficioso para su orden, lo cierto es que don Gonzalo asumió la postura mayoritaria entre los freires de Alcántara, consistente en mantener un interesado equilibrio entre la causa castellana y la portuguesa. Ante la amenazante respuesta de Alfonso XI, el maestre ordenó que no se acogiese al monarca en las fortalezas de su orden, y se refugió en el castillo de Valencia de Alcántara. Según la versión cronística, entonces el maestre de Alcántara pudo ofrecer las fortalezas al rey de Portugal, aunque la documentación pontificia parece contradecir que este extremo se produjera ${ }^{42}$. En cualquier caso, la postura de Gonzalo Martínez fue interpretada como una traición por el monarca castellano, que ordenó la ejecución del maestre rebelde (1339). Previamente, sólo los alcantarinos contrarios a don Gonzalo habían elegido como maestre al freire Nuño Chamizo, acatando así el mandato efectuado en este sentido por Alfonso $\mathrm{XI}^{43}$. Se constata así una división entre los

${ }^{40}$ Sobre la política de Alfonso XI en relación a las órdenes militares vid. Moxó, S., «Relaciones entre la corona y las órdenes militares en el reinado de Alfonso XI», en VII Centenario del Infante D. Fernando de la Cerda, 1275-1975, Ciudad Real, 1976, 117-158.

${ }^{41}$ Crónica de Alfonso XI, pp. 280 y 288; Gran Crónica de Alfonso XI, II, p. 156; Ortega y Cotes, I.J.; Álvarez de Baquedano, F.; Ortega ZúñIga y Aranda, P., Bullarium Ordinis Militiae de Calatrava, pp. 193-196.

${ }^{42}$ Trenchs, J., «Benedicto XII y las Órdenes Militares: regesta de los textos papales», Anuario de Estudios Medievales, 11 (1981), 139-150, pp. 146-147.

${ }^{43}$ Crónica de Alfonso XI, p. 303; Gran Crónica de Alfonso XI, II, pp. 291-300; Ortega y Cotes, Bullarium Ordinis Militiae de Calatrava, pp. 193-196; Ayala, Las Órdenes militares Hispánicas en la Edad Media, pp. 496-499; Novoa Portela, «Los Maestres de la Orden de Alcántara durante los reinados de 
freires, probablemente tamizada y diluida posteriormente por la enérgica actuación del monarca castellano en la resolución del conflicto.

El reinado del hijo y sucesor de Alfonso XI, Pedro I de Castilla (1350-1369), fue una etapa de acusado intervencionismo regio en todas las órdenes castellanas, aunque no todas las intrusiones del monarca generaron una escisión entre los freires de la institución correspondiente ${ }^{44}$. Sí ocurrió al menos en tres ocasiones. La primera de ellas tuvo lugar en 1354, cuando el monarca reunió varios caballeros santiaguistas para que expulsaran del maestrazgo de la orden a su hermanastro don Fadrique y eligieran por nuevo maestre a Juan García de Padilla, hermano de la amante regia María de Padilla. Sin embargo, el antiguo maestre contaba con varios partidarios, entre ellos Gonzalo Mejía, comendador mayor de Castilla, al que el maestre petrista había usurpado su encomienda. Al año siguiente este caballero santiaguista se encargó de matar a Juan García de Padilla en Tarancón. Posteriormente, el maestre Fadrique, acusado de traidor, fue degollado en Sevilla por orden de Pedro I. Para ocupar el maestrazgo vacante, el monarca castellano hizo elegir a García Álvarez de Toledo (1359-1366). El escandaloso intervencionismo regio propició una nueva escisión en el seno de la orden, ya que los opositores a la política petrista eligieron por maestre al propio Gonzalo Mejía ${ }^{45}$.

El maestre calatravo Juan Núñez de Prado se opuso también a la política del monarca y como consecuencia se vio obligado a protegerse en la fortaleza de Calatrava la Nueva y después huir a Alcañiz. En 1355 regresó a la residencia maestral de Almagro, pero el monarca ordenó su encarcelamiento y posterior ejecución, que tuvo lugar en el castillo de Maqueda. Entonces, Pedro I decidió entregar el maestrazgo calatravo a Diego García de Padilla, otro hermano de María de Padilla ${ }^{46}$.

No obstante, una parte importante de los freires calatravos no aceptó el nombramiento y se reunió en Osuna para proceder a la elección de un nuevo maestre, dignidad que recayó en el comendador mayor, Pedro Estébanez Carpentero. Los calatravos rebeldes se aliaron entonces con el sector nobiliario que se oponía al monarca castellano, encabezado por los infantes Enrique y Fadrique y el señor de Alburquerque. El maestre rebelde capturó varios enclaves andaluces de la orden, cercó el convento-fortaleza de Calatrava la Nueva, en el que se encontraba el maestre Padilla, y tomó con facilidad las fortalezas de Almodóvar y Caracuel. Después de dejar bien

Alfonso XI y Pedro I», pp. 321-328; NovoA Portela, F., «Algunas consideraciones sobre los Maestres Alcantarinos desde el nacimiento de la Orden hasta 1350», Revista de Estudios Extremeños, 59 (2003), 1059-1081, pp. 1073-1074 y 1078.

${ }^{44}$ Sabemos, por ejemplo, que las intrusiones de Pedro I en los nombramientos sucesivos de Diego Gutiérrez de Cevallos y de Suero Martínez como maestres de Alcántara suscitaron suspicacias y cierta oposición entre los freires, aunque pronto desaparecieron y no llegó a consolidarse ninguna división. Vid. Novoa Portela, «Los Maestres de la Orden de Alcántara durante los reinados de Alfonso XI y Pedro I», pp. 330-331.

${ }^{45}$ Díaz Martín, L.V., «Los maestres de las órdenes militares en el reinado de Pedro I de Castilla», Hispania, XL (1978), 285-356 pp. 306 y ss.; Porras Arboledas, P.A., La Orden de Santiago en el siglo XV. La Provincia de Castilla, Madrid, 1997, pp. 23-24.

${ }^{46}$ López de Ayala, P., Crónica de Don Pedr o primero, en Pero López de Ayala, Crónicas, edición, prólogo y notas de José-Luis Martín, Barcelona, 1991, pp. 91-93. 
abastecido el convento de Osuna, se desplazó hasta Toro, donde se concentraba el núcleo de opositores al monarca, incluida la reina madre. La ciudad fue tomada por las tropas petristas y el propio Pedro I acabó con la vida del antimaestre. Allí mismo fueron pasados a cuchillo varios de los caballeros de la orden que habían seguido a Pedro Estébanez ${ }^{47}$.

Mientras todo esto ocurría en Castilla, en la Corona de Aragón, a partir del siglo XIV, sus monarcas comenzaron a dar muestras de un notable intervencionismo. Por una parte, respaldaron a los antimaestres calatravos, que desde la fortaleza de Alcañiz, reclamaban su derecho a ocupar la máxima dignidad de la orden. Por otra parte, el objeto fundamental de ese intervencionismo fue la encomienda mayor de Montalbán, cuyos titulares tenían, por concesión papal, el privilegio de no tener que jurar fidelidad y homenaje al maestre de Santiago. El comendador de Montalbán al ser elegido prometía obediencia a su superior jerárquico, el maestre, pero no estaba obligado a nada más. En todo caso, los dieciséis comendadores mayores del siglo XIII habían sido elegidos por decisión conjunta del maestre y los Trece de la orden. Esto explica que durante el primer siglo de la encomienda de Montalbán no hubiera grandes tensiones con la autoridad central santiaguista ${ }^{48}$. Sin embargo, la etapa de intrusismo regio coincidió con un debilitamiento del vínculo existente entre el comendador mayor y el maestre. La autoridad de este último, en opinión de Regina Sáinz de la Maza, comenzó a ser suplantada por la del rey. Por eso, los monarcas exigirán a los comendadores que les presten juramento y homenaje por los bienes que han sido puestos bajo su cuidado: "et insuper facio vobis, dicto domino regi, homagium et fidelitatem manibus et ore" $"$.

En todo caso, los reyes querían que los titulares de Montalbán fueran naturales del territorio de la Corona y estrechos aliados de la política monárquica. Por eso, cuando a principios de 1326 se empezó a difundir la noticia de la grave enfermedad que afectaba al comendador Artal de Huerta, el maestre García Fernández decidió que Blas Maza de Vergua, un aragonés que agradaba al rey Jaime II, ocuparía la encomienda mayor cuando quedara vacante. Sin embargo, por intercesión del infante don Alfonso, el papa se reservó la provisión de la encomienda y nombró para ocuparla a Vidal de Vilanova (agosto de 1327). Jaime II aceptó la decisión papal, ya que el personaje propuesto cumplía los requisitos que interesaban a la monarquía. En cambio, el nuevo maestre Vasco Rodríguez propuso como candidato alternativo a Fernando Lorenzo, castellano y comendador del hospital de Cuenca. Se produjo entonces un cisma en la encomienda de Montalbán, cuya fortaleza fue ocupada por el propio Fernando Lorenzo. El castillo fue entregado por el castellano en 1328, pero el maestre continuó oponiéndose a la candidatura de Vidal de Vilanova. En realidad, lo que se estaba dirimiendo es a quién le correspondía la jurisdicción sobre la encomienda mayor de Aragón. La solución no llegó hasta septiembre de 1331, cuando, a

${ }^{47}$ LóPeZ de Ayala, Crónica de Don Pedro primero, pp. 93-94, 146-148 y 164-167; RADES y ANDRADA, Chronica de Calatraua, fols. 54r-56v.

${ }^{48}$ Sobre esta etapa de la encomienda es imprescindible el libro de Sárnz de la Maza Lasoli, R., La Orden de Santiago en la Corona de Aragón. La encomienda de Montalbán (1210-1327), Zaragoza, 1980.

${ }^{49}$ Sáinz de la Maza Lasoli, R., La Orden de Santiago en la Corona de Aragón (II). La encomienda de Montalbán bajo Vidal de Vilanova (1327-1357), Zaragoza, 1988, pp. 23-24 y doc. 124. 
cambio de la aceptación de su candidato, el nuevo monarca Alfonso el Benigno autorizó al maestre y a sus sucesores a disponer de la encomienda y de sus bienes tras el fallecimiento de Vidal de Vilanova. En todo caso, el elegido debería mostrar su fidelidad al rey: "fidelitate et legalitate nostri et nostrorum in omnibus semper salvis"so.

Sin embargo, tras morir el comendador Fernando Ruiz de Tauste (1352-1355), sucesor de Vidal de Vilanova al frente de la encomienda mayor, tuvo lugar un nuevo cisma entre el castellano Fernando Gómez de Albornoz, candidato apoyado por el papa Inocencio VI y hermano del cardenal Albornoz, y Juan Jiménez de Urrea, consejero de Pedro IV de Aragón. Pese a las disposiciones papales en contra del candidato aragonés, el monarca continuó apoyando a Juan Jiménez de Urrea, al tiempo que consiguió que el maestre don Fadrique le concediera la encomienda. Ante estos hechos, el Papa mostró su incredulidad: "non poteramus credere quod tanta circa hoc posset ingeri difficultas, etiam si preceptoria ipsa tui propii iuris esset"sı, denunciando así la intromisión de Pedro el Ceremonioso en un asunto que no era de su jurisdicción. El extraordinario interés mostrado por Inocencio VI en la cuestión resultó, al final, definitivo ${ }^{52}$, y tanto el maestre como el monarca debieron aceptar a Gómez de Albornoz, que en febrero de 1358 ya figuraba como comendador mayor de Montalbán ${ }^{53}$. Por segunda vez, en el conflicto jurisdiccional entre el pontífice, el maestre y el monarca, se impuso la voluntad del papa.

Medio siglo después, a comienzos de la decimoquinta centuria, Enrique III de Castilla (1390-1406) intervino directamente en la elección del maestre de Calatrava para nombrar a un miembro de su propia familia, Enrique de Villena. Su elección, verificada a principios de 1405 , tuvo lugar en un reducido capítulo calatravo presidido por el monarca castellano y celebrado en el convento toledano de Santa Fe, mientras que otros miembros de la orden se reunían en el convento de Calatrava, como solía ser habitual, y elegían por maestre al comendador mayor Luis González de Guzmán. Enrique III, acompañado del maestre electo, convocó de nuevo el capítulo de los freires favorables a su causa en el convento de Calatrava, para reforzar el derecho al maestrazgo de su candidato. Para entonces, Luis González de Guzmán ya había huido con sus partidarios hacia Alcañiz. La irregularidad de la elección se acrecentaba porque Enrique de Villena estaba casado con María de Albornoz, por lo que hubo que anular precipitadamente el matrimonio alegando impotencia, y además era conde de Cangas y Tineo, título al que hubo de renunciar en favor de la Corona. El nuevo maestre era primo del monarca, ya que los dos eran nietos de Enrique II de Castilla.

Después de la muerte de Enrique III, el capítulo calatravo se volvió a reunir en 1407 y eligió como maestre a Luis González de Guzmán. Se prolongó entonces

${ }^{50}$ Este es la fórmula utilizada por el comendador Fernando Ruiz de Tauste en el juramento realizado en enero de 1353. Vid. Sáinz de la Maza Lasoli, La Orden de Santiago en la Corona de Aragón (II), pp. 37-54, 71 y doc. 53 .

${ }^{51}$ ZunZunEGuI, J., Bulas y cartas secretas de Inocencio VI (1352-1362), Roma, 1970, no 227.

${ }^{52}$ En agosto de 1357, el pontífice volvió a transmitir su queja al monarca y al maestre de Santiago. Publ. ZuNZUNEGUI, Bulas y cartas secretas de Inocencio VI, nº 301 y 302.

${ }^{53}$ Sáinz de la Maza Lasoli, La Orden de Santiago en la Corona de Aragón (II), pp. 69-78. 
la ruptura en el interior de la orden, ya que Enrique de Villena conservó algunos apoyos. En 1414 el capítulo general de la orden del Císter, con el acuerdo del papa, declaró nula la elección de Villena y confirmó a don Luis como maestre. Don Enrique tardó dos años en reconocer la nueva situación. En 1416 se produjo también la confirmación oficial de Luis González de Guzmán por Juan II de Castilla ${ }^{54}$. Se demostraba así que la elección había sido irregular y que el respaldo al candidato regio permaneció el tiempo que duró la vida del monarca que lo había elegido. Actuando de este modo, Enrique III no hacía otra cosa más que continuar con la política del interesado intervencionismo regio en las elecciones maestrales.

En 1443, tras el fallecimiento del maestre calatravo Luis González de Guzmán, los freires eligieron para sucederle al frente del maestrazgo al clavero, Fernando de Padilla. Sin embargo, los infantes de Aragón, que tenían en esos momentos el dominio de la situación política en Castilla, defendían la candidatura al maestrazgo de Alfonso de Aragón, un bastardo de Juan de Navarra. El electo Fernando de Padilla se refugió entonces en la fortaleza de Calatrava la Nueva, con la mayor parte de los comendadores calatravos, para resistir el asedio de las tropas del infante don Enrique de Aragón, integradas, entre otros, por freires santiaguistas y algún comendador de Calatrava. El maestre electo murió accidentalmente por la acción de uno de los defensores en el mismo año 1443, y la fortaleza fue finalmente entregada al infante don Enrique, lo que posibilitó que su sobrino bastardo se convirtiera en maestre de Calatrava ${ }^{55}$.

La elección de Alfonso de Aragón como maestre, sólo se explica por la coacción ejercida por el infante don Enrique, que asistió al capítulo acompañado de cierto número de soldados. No obstante, su maestrazgo efectivo tuvo una escasa duración. En 1444 la posición de los infantes de Aragón se debilitó y se vieron obligados a retirarse del reino castellano. Los freires de la orden protestaron por las irregularidades de la elección, mientras que Alfonso de Aragón se hacía con el control de Alcañiz y de las posesiones aragonesas de la orden, percibiendo las rentas correspondientes al comendador mayor y conservando el título de maestre ${ }^{56}$.

La victoria de Álvaro de Luna en Olmedo (1445) y la muerte del infante don Enrique impidieron que Alfonso de Aragón pudiera recuperar su maestrazgo. Entonces, la designación del nuevo maestre de Calatrava fue un episodio más del intrusismo regio. El elegido para el puesto fue Pedro Girón, perteneciente al círculo privado del príncipe de Asturias, cuya influencia política se había acrecentado ${ }^{57}$. De tal suerte que

${ }^{54}$ Solano Ruiz, E., La Orden de Calatrava en el siglo XV. Los señoríos castellanos de la Orden al fn de la Edad Media, Sevilla, 1978, pp. 63-64; RADES y ANDRADA, Chronica de Calatraua, fols. 65v-66r.

${ }^{55}$ Crónica del Serenísimo Príncipe Don Juan, segundo Rey deste nombr e por Fernán Pérez de Guzmán. Ed. C. Rosell, Crónicas de los Reyes de Castilla, II, «Biblioteca de Autores Españoles», Madrid, 1953, 277-695, pp. 609, 611-613 у 628-629.

${ }^{56}$ Archivo Histórico Nacional, Órdenes Militares, carp. 449, n 128; carp. 467, n 321bis; carp. 468, no 322, 323 y 326; Solano RuIz, La Orden de Calatrava en el siglo XV, pp. 82-84.

${ }^{57}$ Sobre la figura de Pedro Girón vid. Uhagón, F., Órdenes militares. Discursos leídos ante la Real Academia de la Historia, Madrid, 1898, pp. 12-34; O’Callaghan, J.F., «Don Pedro Girón, Master of the Order of Calatrava, 1445-1446», Hispania, 21 (1961), 342-392 (reimpresión en su libro The Spanish Military Order of Calatrava and its Aff liates, VIII); Val Valdivieso, M..I., «Relaciones de Don Pedro 
Juan II convocó al capítulo de la orden para que diera su visto bueno al candidato regio, que posteriormente fue confirmado por las autoridades eclesiásticas correspondientes. Tal circunstancia favoreció la existencia de nuevos cismas en el seno de la institución. Así, desde su elección en septiembre de 1445, Pedro Girón debió enfrentarse a las pretensiones de Alfonso de Aragón, hasta su renuncia en 1455, y tuvo que hacer frente a la oposición interna del comendador mayor Juan Ramírez de Guzmán, que contó en la elección maestral con el respaldo de varios freires calatravos. Este último cisma finalizó en 1448, cuando el comendador mayor fue profusamente compensado por el monarca y el propio maestre a cambio de su renuncia al maestrazgo ${ }^{58}$.

\section{NATURALEZA DE LOS CISMAS DE LAS ÓRDENES MILITARES IBÉRICAS}

\subsection{CISMAS COYUNTURALES}

Los cismas coyunturales se produjeron como consecuencia de una circunstancia puntual y se extinguieron cuando ésta desapareció. Además de los casos ya analizados, los ejemplos más claros de estas escisiones los tenemos en las guerras civiles desarrolladas en los reinos ibéricos o en las contiendas entre reinos cristianos peninsulares. Tres son los enfrentamientos bélicos que propiciaron el desarrollo de cismas coyunturales: la guerra civil castellana (1366-1369), la guerra entre Portugal y Castilla (1383-1385) y la guerra de sucesión castellana (1475-1479).

La primera de ellas fue el más importante enfrentamiento civil del Medievo castellano. La contienda que enfrentó a Pedro I con su hermanastro Enrique de Trastámara fue en realidad un enfrentamiento por la implantación de un modelo de gobierno: el autoritarismo regio que representaba el petrismo frente al pactismo que abanderaba el futuro Enrique II, con el respaldo de buena parte de la nobleza. Con todo, la guerra civil castellana fue una contienda mucha más compleja al represen-

Girón, maestre de Calatrava, con el rey Don Enrique IV», en VII Centenario del infante don Fernando de la Cerda, Ciudad Real, 1976, 159-170; Viña Brito, A., Don Pedro Girón, maestre de Calatrava, y los orígenes de la Casa de Osuna, Tesis Doctoral, Universidad de Sevilla, 1986 (microfichas, Barcelona, 1988); Aguado GonzÁlez, F.J., El ascenso de un linaje castellano en la segunda mitad del siglo XV: los Téllez Girón, condes de Urueña (el origen del señorio de Osuna), 2 vols., Madrid, 1991; Franco Silva, A., «Don Pedro Girón, fundador de la Casa de Osuna (1423-1466)», Osuna entre los tiempos medievales y modernos (siglos XIII-XVIII), Sevilla, 1995, 63-93 (reeditado en su libro Señores y señoríos, Jaén, 1997, 217-260).

${ }^{58}$ Rades y Andrada, Chronica de Calatraua, fol. 72; O'Callaghan, «Don Pedro Girón, master of the Order of Calatrava, 1445-1466», pp. 342-392; PASTOR BoDMER, I., Grandeza y tragedia de un valido. La muerte de don Álvar o de Luna, 2 vols., Madrid, 1992, II, pp. 234-237; CABRERA, E., «En torno a una enconada rivalidad por el Maestrazgo de Calatrava durante el siglo XV», Espacio, Tiempo y Forma. Historia Medieval, 2 (1989), 75-96; CABRERA, E., «El acceso a la dignidad de maestre y las divisiones internas de las Órdenes Militares durante el siglo Xv», en Las Órdenes Militares en la Península Ibérica, I. Edad Media, R. Izquierdo Benito y F. Ruiz Gómez (eds.), Cuenca, 2000, 281-306; CABrera, E., «El maestrazgo de Calatrava, objeto de disputa entre los Guzmán y los Girón durante el siglo XV», en Tierra del Quijote, Tierra de órdenes militares, Ciudad Real, 2007, 7-30. 
tar en cierto modo un episodio de la Guerra de los Cien Años ya que los franceses respaldaron al pretendiente bastardo, mientras que los ingleses apoyaron a Pedro I. Al mismo tiempo, se dilucidaba el juego de fuerzas entre los reinos peninsulares, al apoyar decididamente los aragoneses la causa trastamarista.

En esta guerra civil, las órdenes militares, sometidas a un creciente proceso de secularización, fueron instrumentalizadas por ambos bandos y se vieron implicadas plenamente en la contienda ${ }^{59}$. De hecho, las dos órdenes castellanas más importantes, Calatrava $^{60}$ y Santiago, conocieron cismas por la división entre maestres petristas y maestres trastamaristas. La guerra se inició formalmente en marzo de 1366 con la proclamación de Enrique II como rey de Castilla. El pretendiente consiguió atraerse a su causa a casi todos los máximos mandatarios de las órdenes castellanas. Sus apoyos, los éxitos iniciales y la defensa de la causa nobiliaria, a la que los aristocratizados freires se sentían cada vez más próximos, debieron influir no poco en el cambio de bando por parte de las más altas dignidades de las instituciones. De tal suerte que los maestres petristas de Santiago, García Álvarez de Toledo, y de Calatrava, Diego García de Padilla, se pasaron a la obediencia trastamarista. La actuación concreta del maestre calatravo, aparece perfectamente detallada en el relato del cronista Francisco de Rades:

Estando el Maestre en su villa de Almagro, muy agrauiado del Rey don Pedro, supo que don Enrrique su hermano Conde de Trastamara auia tomado voz y titulo de Rey de Castilla, por la election que muchas ciudades y Grandes del Reyno auian hecho, a titulo de que el Rey don Pedro gouernaua con crueldad y tirania. Supo ansi mesmo que con este titulo auia entrado don Enrrique en la ciudad de Toledo, y los vezinos de ella le auian dado la obediencia, y que pretendia entrar en el Campo de Calatrava, y poner en la possesion del Maestradgo a don Pedro Muñiz de Godoy, a quien el había hecho elegir por Maestre de Calatrava. Sabidas estas nueuas por el Maestre don Diego Garcia de Padilla, (mouido con el temor de ser desposseydo violentamente de su maestradgo, y sientiendose agrauiado del Rey don Pedro por la muerte del Rey de Granada su amigo,) partio de Almagro para Toledo con veynte Caualleros desta Orden, y llegado que fue ala ciudad, beso la mano a don Enrrique, y juro que le seria su vassalo y le serviria en aquella empresa. El Rey don Enrique visto lo que el Maestre don Diego Garcia auia hecho, prometiole que no seria desposseydo de su Maestradgo: y luego mando a don Pedro Muñiz renunciasse en el todo el derecho que dezia tener para ser Maestre: y asi lo renuncio, con que se quedasse con la Encomienda mayor de Alcañiz, y con todo lo que la Mesa Maestral tiene en Aragón, como antes lo posseya ${ }^{61}$.

${ }^{59}$ Un estudio sobre el particular en Ayala Martínez, C. de, «Las órdenes militares ante la guerra civil castellana (1366-1371)», en Poder y Sociedad en la Baja Edad Media Hispánica. Estudios en homenaje al profesor Luis Vicente Díaz Martín, Valladolid, 2002, I, 37-58.

${ }^{60}$ Tratan el tema Estow, C., The Order of Calatrava, its development and its role in the castilian crisis of the mid-fourteenth century, Brandeis University, 1975; y O'CALLAGHAN, J.F., «The Masters of Calatrava and the Castilian Civil War. 1350-1369»», en Die Geistlichen Ritter orden Europas, Sigmaringen, 1980, 353-374.

${ }^{61}$ Rades y Andrada, Chronica de Calatraua, fol. 58r. 
También se pasaron al bando de Enrique II Gómez Pérez de Porres, prior castellano del Hospital, y Melen Suárez, clavero de Alcántara y administrador de la orden por decisión papal. Así que cuando tuvo lugar la batalla decisiva de Nájera (abril de 1367), la mayor parte de las tropas de las órdenes militares estuvieron presentes en el bando del pretendiente. No intervinieron directamente ni el maestre Padilla, recién reconvertido a la causa enriqueña, ni tampoco el santiaguista Gonzalo Mejía, reconocido como único maestre de la orden tras la renuncia de García Álvarez de Toledo. En la batalla, las tropas calatravas estuvieron dirigidas por el cismático maestre enriqueño Pedro Muñiz de Godoy, mientras que las santiaguistas estuvieron al mando de los comendadores mayores de León y Castilla, ya que su maestre estaba defendiendo la causa trastamarista en Andalucía.

Entre los partidarios de Pedro I, sólo encontramos a su fiel Martín López de Córdoba, el depuesto maestre de Alcántara, que contaba con la oposición de un papa cercano a Francia y en consecuencia próximo a los intereses de la causa trastamarista. Junto al otrora maestre, pudo haber participado en la batalla algún freire alcantarino, pero poco más. El triunfo aplastante del petrismo en Nájera, gracias a la decisiva intervención de los arqueros ingleses, propició únicamente la vuelta a su obediencia del vacilante maestre calatravo Diego García de Padilla. La respuesta de Pedro I fue el encarcelamiento del calatravo, que murió en prisión, y la entrega del maestrazgo a Martín López de Córdoba, asegurándose así el control sobre la única orden militar con la que podía contar, aunque desconocemos como reaccionaron los freires calatravos. En cualquier caso, se mantuvo la activa oposición del antimaestre Pedro Muñiz de Godoy que, junto al santiaguista Gonzalo Mejía, se convirtió en un auténtico baluarte de la causa trastamarista. Ambos maestres protagonizaron diversas acciones bélicas y formaron parte del ejército enriqueño en la batalla decisiva de Montiel (1369) ${ }^{62}$.

La muerte de Pedro I y la victoria de Enrique de Trastámara en Montiel suponían en la práctica el fin de la lucha por el trono, aunque la guerra todavía se prolongó hasta 1371. El principal responsable de esta continuación fue el maestre Martín López de Córdoba, que se había hecho fuerte en Carmona, teniendo bajo su custodia a los hijos bastardos de Pedro I y el tesoro personal del monarca fallecido. El líder del petrismo había prometido el trono a Fernando I de Portugal, que aceptó el ofrecimiento esgrimiendo derechos de herencia e intentando aprovechar la coyuntura para arrancar a los castellanos algún territorio fronterizo. Esta circunstancia propició que el recién nombrado maestre alcantarino Melen Suárez, hasta entonces fiel seguidor enriqueño, se pasara a la facción legitimista encabezada por el monarca portugués. La estratégica situación fronteriza del señorío de Alcántara explicaría esta cambiante actitud que, como ya sabemos, no era nueva en la historia de la orden. La cuestión es que la maniobra del maestre propició un cisma en el interior de la institución, ya que los partidarios de los Trastámara, al mando del clavero Diego Martínez, expulsaron al maestre de la villa de Alcántara. La ocasión fue rápidamente aprovechada por el

${ }^{62}$ López de Ayala, Crónica de Don Pedro primero, pp. 321-322, 332, 336, 342-343, 358, 395-396, 403, 408-410, 424-425 y 427; RAdES y ANDrada, Chronica de Alcantara, fol. 30r; ToRres y TAPIA, Crónica de la Orden de Alcántara, II, págs. 120-122; RAdes y ANDRADA, Chronica de Calatraua, fol. 58r-61r. 
monarca castellano para que se procediera a una nueva elección de maestre, dignidad que recayó en la persona del comendador mayor de la orden, Rodrigo Díaz de Vega, estrecho colaborador de Enrique II.

Después de la paz de Alcoutim (primavera de 1371), por la que el monarca portugués reconocía la legitimidad del gobierno de Enrique de Trastámara, sólo quedaba ya el baluarte petrista de Carmona. Finalmente, Martín López de Córdoba decidió entregar la plaza a cambio de ciertas promesas. Enrique II no atendió a lo pactado y ordenó la ejecución del maestre. Se liquidaba así el último foco petrista y se solucionaba el cisma calatravo, cuyo maestrazgo recayó sin discusión en el fiel trastamarista Pedro Muñiz de Godoy ${ }^{63}$.

Unos años más tarde, la guerra luso-castellana de 1383-1385 fue un claro ejemplo de la instrumentalización política y militar de las órdenes por parte de los dos bandos. El desarrollo político de las dos monarquías ibéricas y el papel estratégico de ciertas órdenes en las respectivas fronteras favorecieron la utilización de estas instituciones. La guerra se desencadenó tras la muerte de Fernando I de Portugal, que dejó como heredera de su reino a su hija Beatriz, casada con Juan I de Castilla. La contienda entre castellanos y portugueses fue entonces una guerra de sucesión por el trono, pero también una auténtica guerra civil que desgarró internamente el reino lusitano. Si a todo ello se añade que uno de los pretendientes a la corona portuguesa fue el maestre de la orden de Avís, el futuro Juan I (1383-1433), se entenderá que el protagonismo de las órdenes militares en esta contienda fue ciertamente sobresaliente.

Los enfrentamientos comenzaron a finales de 1383, cuando el maestre de Avís, encargado previamente de vigilar el sector meridional de la frontera, fue nombrado "regidor y defensor del reino", para hacer frente a la invasión de las tropas castellanas que iban a hacer efectiva la herencia de la reina Beatriz. Los restantes maestres de las órdenes militares portuguesas se alinearon con el maestre de Avís, que finalmente, en abril de 1385, sería proclamado rey de Portugal. Sólo el prior lusitano del Hospital, Pedro Álvarez de Pereira, se pasó desde el principio al bando castellano. Esta circunstancia propició un cisma entre los hospitalarios portugueses, ya que los freires partidarios del maestre de Avís eligieron como prior a Álvaro Gonçalves Camelho.

La guerra tuvo como consecuencia la existencia de cismas en todas las órdenes militares portuguesas, expresión manifiesta de la convivencia de dos bandos en el seno de las propias instituciones. En primer lugar, en la propia orden de Avís, algunos de cuyos freires más relevantes apoyaron al bando castellano, como el antimaestre Martín Yáñez de Barbudo ${ }^{64}$ y el comendador mayor Vasco Porcelho, que entregó Vila Viçosa a las tropas de Juan I de Castilla. También ocurrió en una institución tan estrechamente vinculada a la monarquía portuguesa como era la orden de Cristo. De tal suerte que el freire cristeño Gonçalo Tenreiro se autotituló maestre filocastellano. Por último, los santiaguistas portugueses contaron con un bando castellanista, inte-

${ }^{63}$ López de Ayala, P., Crónica de Don Pedr o primero, p. 590; LóPez de Ayala, P., Crónica del r ey Don Enrique, en Pero López de Ayala, Crónicas, edición, prólogo y notas de José-Luis Martín, Barcelona, 1991, pp. 2 y 8-9.

${ }^{64}$ Sobre su figura y su posterior actuación en Castilla vid. Ladero Quesada, M.A., «Portugueses en la frontera de Granada», En la España Medieval, 23 (2000), 67-100, pp. 75-85. 
grado por varios freires y liderado por Fernam d'Amtas, comendador mayor de la orden, que controlaba el importante enclave de Mértola ${ }^{65}$. Los cismas se resolvieron con el triunfo en la guerra de los partidarios de Juan de Avís y la acogida en el reino castellano de algunos de los freires contrarios a su causa.

Algo más de un siglo después, tendría lugar un nuevo enfrentamiento bélico con intervención de tropas castellanas y portuguesas: la guerra de sucesión en Castilla. Tras la muerte de Enrique IV de Castilla en 1474 se abrió una crisis sucesoria, al postularse dos posibles candidatas al trono: la proclamada reina Isabel I, hermanastra del monarca fallecido y ya casada con el infante don Fernando, heredero de la Corona de Aragón, y Juana la Beltraneja, la hija de Enrique IV, respaldada por su tío Alfonso V de Portugal y un sector de la nobleza castellana. En la primavera de 1475 , los portugueses decidían entrar con su ejército en el reino castellano en apoyo de las reivindicaciones de la infanta doña Juana, que fue proclamada reina y contrajo matrimonio con el monarca luso, quien reforzaba con ello sus derechos a la corona castellana. Se iniciaba así la guerra entre los dos reinos hispánicos más occidentales, que era también una contienda civil en la que se dirimían dos modelos diferentes de gobierno: el autoritarismo monárquico de los Reyes Católicos y la limitación del poder real que propugnaba una parte de la nobleza castellana.

La inestabilidad propia de la guerra era el marco adecuado para que se desarrollaran o se consolidaran cismas en todas las órdenes militares de radicación castellana. Así, por ejemplo, en la más importante de ellas, la orden de Santiago, tuvo lugar una escisión entre el maestre Rodrigo Manrique, que controlaba la provincia castellana de la institución, y su oponente Alonso de Cárdenas, reconocido por la provincia leonesa de la orden. El control de esta última era clave para contrarrestar la ofensiva portuguesa. Ambos maestres eran partidarios de los Reyes Católicos, razón por la cual los monarcas utilizaron al candidato leonés para atacar el territorio portugués y defender las posiciones de la zona fronteriza, mientras que el castellano era empleado para combatir los señoríos de los Pacheco-Girón, partidarios de doña Juana. La cuestión del cisma se resolvió en 1476, con la muerte de Rodrigo Manrique. Tras un año, durante el cual la administración del maestrazgo estuvo en manos del rey Fernando, en noviembre de 1477, Alonso de Cárdenas fue elegido como maestre por el capítulo de la orden ${ }^{66}$.

Para la segunda de las órdenes en importancia, la de Calatrava, la guerra tuvo dos importantes consecuencias. En primer lugar, se produjo una división entre los que

${ }^{65}$ Lopes, F., Crónica de D. João I segundo o códice $n^{\circ} 352$ do Arquivo Nacional da Torre do Tombo, 2 vols., Barcelos, 1983, I, pp. 16, 20, 121, 130, 174, 182, 185-192, 200-204, 226, 296, 310-311, 343-344 y 363-364, II, p. 160; López de Ayala, P., Crónica del rey Don Juan, en Pero López de Ayala, Crónicas, edición, prólogo y notas de José-Luis Martín, Barcelona, 1991, pp. 561-566, 569-571, 573, 586 y 588; Rades y Andrada, Chronica de Alcantara, fol. 32v; Torres y TAPIA, Crónica de la Orden de Alcántara, II, pp. 150-151.

${ }^{66}$ Rades y Andrada, Chronica de Sanctiago, fols. 66v-71r; Orozco, P. de y J. de la Parra, [Primera] Historia de la Orden de Santiago, pp. 393-394 y 403; JAVIERRE Mur, A., «Fernando el Católico y las Órdenes militares Españolas», en Fernando el Católico. Vida y Obra. V Congreso de Historia de la Corona de Aragón. Estudios, I, Zaragoza, 1955, 285-300, pp. 295-298; PINo GARCÍA, J.L. DEL, Extremadura en las luchas políticas del siglo XV, Badajoz, 1994, pp. 286-288. 
ocupaban el triunvirato de poder de la institución: el maestre, el comendador mayor y el clavero. El maestre Rodrigo Téllez Girón, defendiendo más los intereses familiares que los de su propia orden, se inclinó claramente a favor del bando de Juana la Beltraneja. Sin embargo, poco después, el comendador mayor Fernán Gómez de Guzmán y el clavero García López de Padilla se pasaron al bando isabelino. El maestre calatravo se mantuvo en el bando portugués, pero no pudo aportar ninguna ayuda al ejército de Alfonso V, ya que sus tierras fueron atacadas, siguiendo órdenes de los reyes castellanos, por parte de Rodrigo Manrique, maestre de Santiago, y del conde de Cabra ${ }^{67}$. En mayo de 1476, tras los sucesivos reveses de las tropas lusas y el abandono de la causa de doña Juana por parte de algunos nobles, Rodrigo Téllez Girón llegó a un pacto con Isabel y Fernando para conservar su maestrazgo y todos los derechos que le correspondían a su orden, a cambio de reconocerles como monarcas ${ }^{68}$.

La segunda consecuencia fue la resurrección de las antiguas aspiraciones de Alfonso de Aragón, antes maestre calatravo (1443-1445), de ocupar nuevamente la máxima dignidad de la orden. Pasó a Castilla, tomó de nuevo el título de maestre y como partidario del bando de su hermanastro el rey Fernando, intervino con éxito en la contienda militar. Sin embargo, el perdón concedido por los monarcas a Rodrigo Téllez Girón tuvo como consecuencia la renuncia Alfonso de Aragón al maestrazgo a cambio de amplias compensaciones ${ }^{69}$.

El papel de la tercera de las órdenes castellanas, la de Alcántara, era fundamental, por la estratégica ubicación de una parte importante de sus señoríos, situados en la frontera con Portugal. Por eso los Reyes Católicos no renunciaron a utilizar el potencial de la institución, a pesar de que estuviera desgarrada en su interior por un cisma, propiciado por el aspirante Francisco de Solís, que controlaba las principales fortalezas de la orden y había hecho prisionero al maestre Alonso de Monroy. El electo Francisco de Solís había tomado la plaza portuguesa de Ugüela, y por eso los monarcas le encomendaron la defensa de su causa frente a los portugueses en la región extremeña. Sin embargo, la muerte de Solís defendiendo Ugüela en 1475, propició que fuera de nuevo Monroy el que retomara el gobierno efectivo de la orden de Alcántara, y con ello la responsabilidad que Isabel y Fernando habían encomendado a su oponente ${ }^{70}$.

${ }^{67}$ Crónica de los Señores Reyes Católicos Don Fernando y Doña Isabel de Castilla y deAragón escrita por su cronista Hernando del Pulgar, ed. C. Rosell, Crónicas de los Reyes de Castilla, III, «Biblioteca de Autores Españoles», Madrid, 1953, pp. 259-260, 267 y 274-275.

${ }^{68}$ Rades y Andrada, Chronica de Calatraua, fols. 79r-80v; Solano, La Orden de Calatrava en el siglo $X V$, pp. 109-114.

${ }^{69}$ Real Academia de la Historia, Colección Salazar, sign. I-35, fols. 27 y 29-30; Solano, La Orden de Calatrava en el siglo XV, pp. 112-113.

${ }^{70}$ Torre, A. y SuÁrez, L., Documentos referentes a las relaciones con Portugal durante el reinado de los Reyes Católicos, Valladolid, 1958, n 25, 28, 29, 34 y 60; Baquero Moreno, H.C., «Os conflitos fronteriços entre D. Alfonso V e os Reis Católicos», Revista da Facultade de Letras, Oporto, X (1993), pp. 103116; Torres y Tapia, Crónica de la Orden de Alcántara, II, pp. 424 y ss.; RADES y ANDRADA, Chronica de Alcantara, fols. 48v y ss.; Gerbet, M.C., «Fray Alonso de Monroy, Maître dechu de l'Ordre d'Alcántara», en Las Órdenes Militares en el Mediterráneo Occidental (siglos XIII-XVIII), Madrid, 1989, 139-154. 
Sin embargo, el fallecimiento de Solís no suponía el final de las divisiones en la institución. La oposición al maestre Alonso de Monroy estaba liderada ahora por el antimaestre Juan de Zúñiga, hijo del poderoso duque de Arévalo, partidario de los portugueses, que controlaba importantes fortalezas de la orden, incluida la sede conventual de Alcántara. Estas posiciones eran claves en la guerra con Portugal, y por eso los Reyes Católicos negociaron con los Zúñiga para garantizarse su adhesión a cambio del apoyo al aspirante para el maestrazgo de Alcántara. Juan de Zúñiga contaba además con la aprobación del papa Sixto IV (1471-1484). La reacción de Alonso Monroy fue pasarse con las fortalezas que controlaba, entre las que estaban las de Piedrabuena, Belvís y Mayorga, al servicio del rey de Portugal. Para colaborar con Monroy, y su aliada la condesa de Medellín, Alfonso V envió al obispo de Évora al frente de un nutrido contingente. Poco después, en febrero de 1479, tendría lugar la batalla de Albuera, en la que el maestre santiaguista llevó a la victoria al ejército castellano frente a los portugueses y sus aliados, contribuyendo a que la contienda se decantara a favor de los Reyes Católicos. Más tarde, Alonso de Cárdenas se ocupó de asediar Mérida, estratégica plaza que permanecía en manos del partido juanista. El debilitamiento de las posiciones de los portugueses y la creciente reducción de sus partidarios castellanos propiciaron que se alcanzara la definitiva paz de Alcaçovas antes de que terminara el verano de 1479. Con ello, Juan de Zúñiga se aseguraba el maestrazgo de Alcántara, que ostentaba desde $1477^{71}$.

Finalmente, los hospitalarios castellanos también experimentaron una notable fractura, que se había gestado en los años finales del reinado de Enrique IV (14541474). La mayor parte del priorato castellano del Hospital estaba en manos de Álvaro de Zúñiga, que se había decantado por el bando isabelino y combatió a sus órdenes en la guerra de sucesión. No obstante, su rival, y anterior prior, Juan de Valenzuela, que participó activamente en la guerra en el bando portugués, controlaba los señoríos del valle del Guareña y la emblemática fortaleza de Consuegra. El castillo de Castronuño y, con él, las posiciones sanjuanistas del Guareña fueron tomadas por el ejército fiel a los Reyes Católicos y restituidas al prior Álvaro de Zúñiga. Sin embargo, la definitiva resolución del cisma hubo de esperar hasta 1488, cuando el maestre hospitalario sentenció a favor de don Álvaro en el pleito por el priorato castellano ${ }^{72}$.

\subsection{CISMAS CONSOLIDADOS}

Para que se produjera la consolidación de un cisma era necesario el apoyo de un poder ajeno al organigrama de la orden. Si este poder era una monarquía externa al lugar donde radicaba la sede de la institución, las posibilidades de consolidar la ruptura eran mucho mayores.

${ }^{71}$ Torres y TAPIA, Crónica de la Orden de Alcántara, II, pp. 432-448; RAdES y ANDRADA, Chronica de Alcantara, fols. 48v-53r; Ortega y Cotes, I.J., Bullarium Ordinis Militiae de Alcantara, Madrid, 1759, pp. 227-232; Gerbet, M.C., «Fray Alonso de Monroy, Maître dechu de l'Ordre d'Alcántara», pp. 148-154; Palacios, Colección Diplomática Medieval de la Orden de Alcántara, II, nº 1179-1229, 1244 y 1254.

${ }^{72}$ Barquero, C., Los caballeros hospitalarios en la España de los Reyes Católicos (1474-1516),Gijón, 2006, pp. 31-34. 
Paradigma evidente de este tipo de cismas son las numerosas manifestaciones rupturistas verificadas en el convento mayor de la orden de Calatrava en Alcañiz (Aragón). Durante algunos períodos, el cisma tuvo todas las características para llegar a convertirse en irreversible, pero no lo hizo porque a la monarquía aragonesa le interesó más mantener la teórica dependencia respecto a la sede central castellana y utilizarla, cuando le convenía, como arma política y económica, amenazando con su independencia y la retención de sus rentas. Algo similar ocurrió con la encomienda santiaguista de Montalbán, también radicada en el reino de Aragón. Sin embargo, su tamaño más reducido, tanto en términos absolutos como en términos relativos, podría explicar que no fuera utilizada, como si lo fue Alcañiz, como sede de cismas frente a los maestres de Santiago. En cambio, como ya hemos analizado, los monarcas aragoneses respaldaron a sus propios candidatos para ocupar la encomienda de Montalbán, frente a los candidatos castellanos.

Por su parte, la orden de Calatrava fue, desde sus orígenes, una institución fundamentalmente castellana, cuya sede principal estuvo siempre en Castilla y allí se situaban también la mayor parte de sus señoríos jurisdiccionales, bienes patrimoniales y rentas. Fuera del ámbito castellano, Calatrava tuvo un cierto número de propiedades en el reino de León y la Corona de Aragón, con una presencia mucho más marginal en los reinos de Portugal y Navarra. Después de 1218, cuando las propiedades leonesas pasaron a manos de la orden de San Julián del Pereiro-Alcántara, la Corona de Aragón se convirtió en el único territorio que, fuera de Castilla, contaba con propiedades calatravas de cierta relevancia. El núcleo principal de estas propiedades, la encomienda mayor de Alcañiz, se mantuvo bajo el señorío calatravo durante toda la Edad Media. Alcañiz era un convento fortaleza que constituía la única encomienda mayor de carácter territorial de Calatrava, ya que la encomienda mayor de la orden afectaba a toda la institución. Alcañiz articulaba las posesiones calatravas de la Corona, particularmente concentradas en la comarca del Bajo Aragón, donde estaba enclavado el convento, a las que se añadían otras propiedades en el reino valenciano. Con esta configuración, y el respaldo de la monarquía aragonesa, desde Alcañiz se podía producir un cisma o consolidar uno ya existente.

En este sentido, hemos tenido ocasión de aludir a varios ejemplos. Así, entre los casos más significativos de cismas desarrollados desde la encomienda de Alcañiz se encuentran los de los tres maestres de la orden que, después de ocupar legítimamente la máxima dignidad de la institución, continuaron reivindicado su condición de maestres desde la fortaleza turolense. Se trata de Martín Martínez (1199-1206; 1206c. 1211 en Alcañiz), García López de Padilla (1297-1329; 1329-1336 en Alcañiz) y Alfonso de Aragón (1443-1445; 1445-1455 en Alcañiz). En cambio, otros freires de la orden utilizaron la encomienda mayor aragonesa como base material para reivindicar un maestrazgo que obtendrían con posterioridad. Eso es precisamente lo que ocurrió en el caso de los maestres Pedro Muñiz de Godoy (1371-1384) y Luis González de Guzmán (1414-1443)

En cualquier caso, la mayor parte de los cismas que se desarrollaron en la encomienda mayor aragonesa no fueron causados por una intervención directa de los

${ }^{73}$ Caruana Gómez de Barreda, «La Orden de Calatrava en Alcañiz», pp. 59-133. 
monarcas de la Corona. Los cismas, se había producido por alguna de las causas que hemos analizado con anterioridad, pero el respaldo de los reyes de Aragón contribuyó a consolidarlos y prolongarlos en el tiempo. Sólo podemos documentar un ejemplo claro del desarrollo de un cisma como consecuencia de la intervención directa de un monarca aragonés, aunque no conviene descartar la existencia de alguno más. Se trata del cisma provocado por el nombramiento del comendador mayor de Alcañiz, que había recaído en la persona de Pedro Muñiz de Godoy, comendador de Caracuel, enemigo del rey de Castilla. El problema residía en que el castellano esgrimía que el nombramiento le pertenecía al maestre de Calatrava y no al monarca aragonés. Naturalmente, detrás de esta argumentación estaba dirimiéndose a quién correspondía la jurisdicción sobre las órdenes ibéricas. Cada monarca quería tener el máximo nivel de competencias sobre las instituciones radicadas en su reino, pero también quería extenderlo hacia las órdenes militares de los reinos vecinos siempre que sus sedes maestrales estuvieran en su territorio. Así, al reivindicar la jurisdicción del maestre de Calatrava sobre sus freires aragoneses, Pedro I estaba afirmando indirectamente la extensión de su jurisdicción a las ramificaciones aragonesas de las órdenes militares castellanas, en tanto en cuanto el maestre calatravo era vasallo del rey de Castilla.

Precisamente, el nombramiento de Pedro Muñiz de Godoy como comendador de Alcañiz fue uno de los argumentos esgrimidos por Pedro I para justificar el desarrollo de la denominada guerra de los Dos Pedros (1356-1365) ${ }^{74}$. El cisma se prolongaría con posterioridad, ya inmerso en el contexto de la guerra civil castellana de 1366-1369, cuya resolución llevaría a Pedro Muñiz de Godoy a ocupar el maestrazgo de Calatrava.

Por otra parte, los frecuentes cismas protagonizados por la encomienda calatrava de Alcañiz significaron la pérdida del control sobre las rentas de esa circunscripción y muy particularmente sobre las responsiones que sus titulares debían enviar a los maestres. Idéntica circunstancia, aunque en menos ocasiones, se repitió con los cismas en la encomienda santiaguista de Montalbán.

\subsection{CISMAS IRREVERSIBLES}

Los cismas irreversibles sólo podían conseguirse con el apoyo incondicional de un monarca externo al reino donde la orden tenía establecida su sede. Precisamente, por su carácter irreversible, estos cismas se traducían en la creación de nuevas órdenes militares. En la Península Ibérica, contamos con dos ejemplos de cismas irreversibles: los que provocaron el nacimiento de las órdenes de Monfragüe y de Santiago de Portugal.

El primer ejemplo fue el cisma de la orden de Santa María de Montegaudio, nacida en 1174, con el respaldo de Alfonso II de Aragón, para defender la frontera meridional frente a los musulmanes ${ }^{75}$. En el otoño de 1186, la debilidad estructural, acrecentada por el rechazo del capítulo general de la orden del Císter a aceptar plenamente a la nueva institución, desembocaría en un primer intento de fusionar la orden de Montegaudio con la del Temple, la orden militar por excelencia, bien consolidada

${ }^{74}$ López de Ayala, Crónica de Don Pedro primero, pp. 173-174.

${ }^{75}$ Ayala, Las Órdenes militares Hispánicas en la Edad Media, pp. 103-105. 
tanto en Tierra Santa como en Occidente, y asentada desde tiempo atrás en el reino aragonés. La iniciativa, que no contó con la participación del fundador, el conde don Rodrigo $^{76}$, terminó fracasando debido a la existencia de una división en el interior de la orden y a la más que probable oposición de Alfonso II, que quería salvar a toda costa el proyecto original de una orden genuinamente aragonesa al servicio, fundamentalmente, de los intereses de la monarquía. Con este objetivo, en 1187 el monarca aragonés donó a la orden militar la fortaleza de Villel, y un año más tarde la fusionó con el hospital del Santo Redentor de Teruel. Se trataba de una auténtica refundación de la institución, que pasó a denominarse orden del Santo Redentor, al trasladar su sede a este hospital turolense dedicado a la redención de cautivos cristianos.

La muerte del conde Rodrigo tuvo lugar en 1188, la misma fecha de la refundación de la orden. Ambos acontecimientos contribuyeron probablemente a que se produjera un cisma en el interior de la institución, entre una facción aragonesa, encabezada por el maestre Fralmo de Lucca, y otra castellana, liderada por Rodrigo González, comendador de la orden en Castilla y lugarteniente del maestre. Materialización evidente de la escisión fue la deposición de frey Fralmo y su sustitución por el comendador castellano. Sin embargo, Alfonso II no estaba dispuesto a admitir que su proyecto original trasladará su sede al vecino reino occidental. Por eso, frey Fralmo recuperó de forma irregular el maestrazgo, renunció a la regla cisterciense y promovió la fusión con la orden del Temple, que terminó por consumarse en 1196.

Rodrigo González aprovechó la integración de la orden de Montegaudio en la del Temple para consumar la independencia de la rama castellana, que a partir de esa fecha, y gracias al apoyo de Alfonso VIII de Castilla, situó su sede maestral en la fortaleza de Monfragüe y comenzó a ser conocida con el nombre de este castillo extremeño. El monarca castellano había explotado la coyuntura favorable para donar a los freires castellanos Monfragüe, baluarte estratégico fundamental en la defensa del flanco occidental del reino, máxime cuando este sector había sentido con fuerza las consecuencias de la devastadora campaña almohade del verano de $1196^{77}$.

No obstante, las reclamaciones templarias sobre la herencia que correspondía a Montegaudio acabaron por propiciar como acción más factible la integración de los freires de Monfragüe en la orden de Calatrava. En 1215 el capítulo general de la orden del Císter aprobó la incorporación. Sin embargo, una parte importante de los freires de Monfragüe no parecían especialmente inclinados a hacer efectiva esta fusión. Ante esta situación, en 1221 Fernando III entregó a la orden de Calatrava la fortaleza de Monfragüe y las restantes propiedades pertenecientes a la institución del mismo nombre ${ }^{78}$. El monarca castellano tomaba así claramente partido, al preferir decantarse por el reforzamiento de la más genuina orden castellana frente a la posibilidad de que la pequeña institución asentada en la frontera suroccidental de su reino fuera fagocitada por la poderosa orden del Temple. Sin embargo, la decisión

${ }^{76}$ Sobre este personaje vid. SÁnchez PAGín, J.M., «El conde don Rodrigo Álvarez de Sarria, fundador de la orden militar de Monte Gaudio», Compostellanum, 28 (1983), 273-298.

${ }^{77}$ García Fitz, F., Castilla y León frente al Islam. Estrategias de expansión y tácticas militares (siglos XI-XIII), Sevilla, 1998, pp. 201-203 y 448.

${ }^{78}$ GonzÁlez, J., Reinado y diplomas de Fernando III, 3 vols., Córdoba, 1980-1983-1986, II, nº 133. 
regia contó con la oposición manifiesta de varios freires de Monfragüe, que querían preservar su autonomía y persistieron en sus reivindicaciones. Para afrontar el problema, en marzo de 1225, Honorio III comisionó al obispo, deán y arcediano de Burgos para que resolvieran el conflicto entre los freires de la orden de Monfragüe y el maestre y los freires de Calatrava ${ }^{79}$. El pleito se alargó hasta 1234, pero finalmente la orden de Monfragüe se extinguió y sus efectivos humanos y bienes materiales se integraron definitivamente en la orden de Calatrava ${ }^{80}$.

Décadas después, a finales del siglo xIII, y con el respaldo de la monarquía lusa, se inició el proceso que llevaría a los santiaguistas portugueses a escindirse y convertirse en una orden independiente de hecho. La autonomía con la que actuaba la encomienda mayor de Portugal respecto a los maestres de la orden propició que en 1290 el papa Nicolás IV (1288-1292) autorizara a los santiaguistas portugueses a elegir maestre propio ${ }^{81}$. El designado fue el comendador mayor de Mértola, núcleo principal de los santiaguistas lusitanos desde 1245. La licencia papal sería revocada por sus sucesores y coyunturalmente los freires portugueses volvieron a la dependencia del maestre castellano.

Con todo, la autonomía con la que actuaban los santiaguistas de Portugal se acrecentó en las primeras décadas del siglo XIV. En varias delegaciones enviadas a Roma entre 1317 y 1320 los freires lusos subrayaron su tradición de servicio al rey de Portugal y el desvío de algunas rentas hacia los maestres castellanos, al tiempo que hacían responsables a estos últimos de la dilapidación de su patrimonio. De tal suerte que se terminó por consolidar la existencia de un maestre portugués sometido a la visita de los maestres de Uclés.

Los Establecimientos de 1327 supusieron un auténtico hito en el proceso de autonomía de la orden de Santiago de Portugal. Se trata de unos estatutos inspirados por la monarquía lusa, que incluían la creación de una mesa maestral privativa, dotando a su titular de importantes recursos y reforzando su independencia con respecto a los maestres de Uclés. La normativa suponía una reorganización integral de los santiaguistas portugueses, subordinando a los freires a los intereses de la Corona. Los Establecimientos consagraban también el intervencionismo de los monarcas en los asuntos internos de la orden como la enajenación de bienes, la destitución de los comendadores, la reforma de la institución y, naturalmente, la elección de los maestres, que debían ser necesariamente personas afectas a la causa regia. En la práctica, la normativa establecía la sumisión de la orden a la monarquía, convirtiéndola en instrumento de los intereses del reino. En cualquier caso, la teórica supeditación a los maestres castellanos no desapareció definitivamente hasta 1452, cuando el papa Nicolás V (1447-1455) eximió a los santiaguistas portugueses de la jurisdicción y el derecho de visita que tenía la orden castellana de Santiago ${ }^{82}$.

\footnotetext{
${ }^{79}$ Mansilla, La documentación pontif cia de Honorio III, $\mathrm{n}^{\circ} 542$.

${ }^{80}$ Para todo lo anterior vid. Forey, A., «The Order of Mountjoy», Speculum, 46 (1971), pp. 250-266. Se trata del trabajo más importante sobre esta institución.

${ }^{81}$ Lomax, D.W., «El rey don Diniz de Portugal y la Orden de Santiago», Hidalguía, 30 (1982), pp. 477-487.

${ }^{82}$ Cunha, M.R. DE Sousa, A Ordem Militar de Santiago (das origens a 1327), Oporto, 1991; Ayala Martínez, C. de, «La escisión de los santiaguistas portugueses. Algunas notas sobre los establecimientos
} 


\section{CONSECUENCIAS DE LOS CISMAS EN LAS ÓRDENES MILITARES}

\subsection{DEBILITAMIENTO DEL MAESTRAZGO Y DE LA PROPIA INSTITUCIÓN}

La primera consecuencia que provocan los cismas es el debilitamiento del poder maestral y de la propia institución a la que afectan. Los maestres pierden poder político, militar, social y económico, al pasar a controlar un menor número de propiedades y de freires de la orden. Naturalmente, las órdenes, divididas en dos facciones, pierden peso específico en la vida del reino. Estas circunstancias se agudizaban en la medida en que los cismas se prolongaban en el tiempo.

Además, cuando el cisma se resolvía se hacía en no pocas ocasiones a costa de compensaciones económicas para el antimaestre o candidato alternativo que mermaban las rentas o el patrimonio que dependía del maestre. Si ese candidato no era miembro de la orden, la institución en su conjunto experimentaba una pérdida económica. Asimismo, los cismas provocaban algunas veces la pérdida de miembros de la orden, que en ocasiones se encontraban entre los freires más cualificados.

La división que tuvo lugar en la orden de Calatrava en la década de 1440 constituye un arquetipo de cisma de nefastas consecuencias para el maestrazgo y para la institución. El cisma se saldó con la pérdida de varios efectivos de la orden, con la autonomía temporal de la rama aragonesa de la institución -en manos de Alfonso de Aragón- y con importantes compensaciones económicas a favor del comendador mayor Juan Ramírez de Guzmán, a cambio de que renunciara al maestrazgo. Además de las importantes concesiones regias, la renuncia al maestrazgo del comendador Guzmán tuvo como contrapartida el pago de 150.000 maravedís anuales de las rentas pertenecientes al maestrazgo calatravo en las minas de Almadén. El comendador mayor pudo conservar también las encomiendas que él, sus hijos y sus sobrinos tuvieran por concesión del maestre Luis González de Guzmán o de alguno de sus antecesores, pero debió hacer entrega de las restantes propiedades de la orden al nuevo maestre Pedro Girón, particularmente de la fortaleza de Zorita ${ }^{83}$. En definitiva el cisma se liquidaba con una importante contraprestación económica y con la imposibilidad de disponer de las encomiendas que controlaban Juan Ramírez de Guzmán y sus familiares, que, según Rades, eran las encomiendas de Osuna, Agudo, Abenojar, Otos, Mestanza, Caracuel y Guadalerza ${ }^{84}$.

Finalmente, la creación de nuevas órdenes militares a partir de otra ya existente suponía la pérdida permanente de rentas, patrimonio y efectivos humanos para esta última, con la consecuente disminución de la base territorial y del prestigio de la institución.

de 1327», Historia, Instituciones, Documentos, 24 (1997), pp. 53-69; BArbosa, I.M. Lago, «A Ordem de Santiago em Portugal nos finais da Idade Média (Normativa e prática)», Militarium Ordinum Analecta. As Ordens de Cristo e de Santiago no início da Época Moderna: A Normativa, 2 (1998), pp. 93-288.

${ }^{83}$ Crónica del Serenísimo Príncipe Don Juan, pp. 636 y 641-650; O’Callaghan, «Don Pedro Girón, master of the Order of Calatrava, 1445-1466», pp. 356-359.

${ }^{84}$ Rades y Andrada, Chronica de Calatraua, fols. 72v-73r. 


\subsection{INCREMENTO DEL CONTROL MONÁRQUICO SOBRE LAS ÓRDENES}

Otra consecuencia notable de los cismas fue el incremento del control monárquico sobre las órdenes militares. La intervención de los reyes resultó determinante, en no pocas ocasiones, para la resolución del cisma. Esta circunstancia propició que, a partir de mediados del siglo XIII, los monarcas utilizaran todo el poder del que disponían para acrecentar su intervencionismo en las órdenes. El rey podía utilizar su poder político y económico para compensar a los opositores al maestre.

El prototipo más revelador de la utilización de los recursos económicos de la Corona para resolver un cisma lo tenemos, una vez más, en la crisis calatrava de 1445. En la elección maestral de ese año, Pedro Girón recibió el voto del clavero García López de Padilla, de 22 comendadores y de otros muchos freires clérigos y legos. Sin embargo, el comendador mayor Juan Ramírez de Guzmán, que nunca había abandonado sus aspiraciones de acceder al maestrazgo, tuvo el respaldo de tres comendadores, cuatro caballeros y 14 clérigos, además del control sobre la tierra de Zorita, las villas de Osuna y Martos y otras plazas andaluzas que había conquistado con la fuerza de las armas. Sin embargo, el rápido reconocimiento de Pedro Girón como legítimo maestre por parte de Juan II de Castilla, el abad de Morimond y el papa Eugenio IV, facilitó que se llegara a una primera avenencia en 1446. Tras ciertas discordias entre los dos candidatos, el acuerdo definitivo se firmó en el verano de 1448. El interés mostrado por Juan II de Castilla y don Enrique, el príncipe de Asturias, fue decisivo para que se llegase a una concordia.

El comendador mayor, que entonces era miembro del Consejo Real, renunció al maestrazgo calatravo, reconoció a Pedro Girón como legítimo maestre y le prestó el correspondiente vasallaje: "prometo al dicho señor maestre guardar su seruiçio e estado con mi persona e casa le seguir contra todas e qualesquier personas de qualquier estado, condiçión, preminençia o dignidad que contra él fuere". En contrapartida, Juan Ramírez de Guzmán recibiría, por concesión regia, 100.000 maravedís anuales con carácter vitalicio, 50.000 maravedís anuales por juro de heredad y 300 vasallos cabezas de familia por juro de heredad ${ }^{85}$. Así, los sectores próximos al círculo monárquico colocaban a uno de los suyos al frente de una de las instituciones más importantes del reino de Castilla. Las rentas y el patrimonio entregado a Juan Ramírez de Guzmán por la Corona aseguraron el maestrazgo a Pedro Girón.

En definitiva, el control monárquico sobre las órdenes militares ibéricas, que habían nacido gracias al apoyo de los propios reyes, se fue paulatinamente incrementando, tanto en el reino castellano-leonés como en Portugal. De tal suerte que el proceso de control regio sobre las órdenes culminaría con la incorporación de los maestrazgos a la Corona ${ }^{86}$.

${ }^{85}$ Crónica del Serenísimo Príncipe Don Juan, pp. 636 y 641-650; O’Callaghan, «Don Pedro Girón, master of the Order of Calatrava, 1445-1466», pp. 356-359.

${ }^{86}$ Sobre el tema vid. Ayala, Las Órdenes militares Hispánicas en la Edad Media (siglos XII-XV), pp. 714-766; Rodríguez-Picavea, Los monjes guerreros en los reinos hispánicos. Las órdenes militares en la Península Ibérica durante la Edad Media, pp. 398-434. 